\title{
Core Elements of General Supportive Care for Patients with Sepsis and Septic Shock in Resource-Limited Settings
}

\author{
Mervyn Mer, Marcus J. Schultz, Neill K. J. Adhikari, \\ Arthur Kwizera, Sanjib Mohanty, Arjen M. Dondorp, \\ Ary Serpa Neto, and Jacobus Preller
}

\footnotetext{
M. Mer

Divisions of Critical Care and Pulmonology, Department of Medicine, Faculty of Health Sciences, Charlotte Maxeke Johannesburg Academic Hospital, University of the Witwatersrand, Johannesburg, South Africa

Wits-UQ Critical Care Infection Collaboration, Faculty of Health Sciences, Charlotte Maxeke Johannesburg Academic Hospital, University of the Witwatersrand, Johannesburg, South Africa
}

M. J. Schultz $(\square)$

Department of Intensive Care, Academic Medical Center, University of Amsterdam, Amsterdam, The Netherlands

Laboratory of Experimental Intensive Care and Anesthesiology (L.E.I.C.A.), Academic Medical Center, University of Amsterdam, Amsterdam, The Netherlands

Mahidol-Oxford Tropical Medicine Research Unit (MORU), Faculty of Tropical Medicine, Mahidol University, Bangkok, Thailand

N. K. J. Adhikari

Department of Critical Care Medicine, Sunnybrook Health Sciences Centre,

Toronto, ON, Canada

Interdepartmental Division of Critical Care, University of Toronto, Toronto, ON, Canada

A. Kwizera

Intensive Care Unit, Mulago National Referral Hospital, Makerere University College of Health Sciences, Kampala, Uganda

Department of Anesthesia, Mulago National Referral Hospital, Makerere University College of Health Sciences, Kampala, Uganda

S. Mohanty

Intensive Care Unit, Ispat General Hospital, Rourkela, Sundargarh, Odisha, India

A. M. Dondorp

Mahidol-Oxford Tropical Medicine Research Unit (MORU), Faculty of Tropical Medicine, Mahidol University, Bangkok, Thailand

A. M. Dondorp et al. (eds.), Sepsis Management in Resource-limited Settings, https://doi.org/10.1007/978-3-030-03143-5_5 

A. Serpa Neto
Deptartment of Critical Care Medicine, Hospital Israelita Albert Einstein, São Paulo, Brazil
J. Preller
Intensive Care Unit, Addenbrooke's Hospital, Cambridge University Hospitals NHS
Foundation Trust, Cambridge, UK

\subsection{Introduction}

Evidence informing the management of patients with sepsis and septic shock mainly derives from research in resource-rich settings. Knowledge translation to intensive care units (ICUs) in resource-limited settings is limited by restricted availability of skilled staff, equipment, and laboratory support, compounded by infrastructure and logistical challenges. Consequently, we developed recommendations relating to core elements of general supportive care for patients with sepsis and septic shock in resource-limited settings. Our recommendations are built on guidelines from the Surviving Sepsis Campaign [1] and the Global Intensive Care Working Group of the European Society of Intensive Care Medicine [2], as well as on a search for additional recent evidence from resource-limited ICUs.

Clinicians with direct experience in resource-limited ICUs developed recommendations by adapting the Grading of Recommendations Assessment, Development and Evaluation (GRADE) tools [3]. Similar to our group's previous publications (e.g., see [4]), quality of evidence was assessed as high to very low. Recommendations were stated as strong or weak based additionally on indirectness of evidence, magnitude of effects, and availability, feasibility, and safety in resource-limited ICUs. We consulted the World Health Organization's Essential Medicines List when considering the availability of medications (available at http:/www.who.int/medicines/ publications/essentialmedicines/en/). When necessary, evidence from resource-rich ICUs was adopted after pragmatic experience-based appraisal (see online supplement). We also made several good practice statements [5]. Recommendations and suggestions are summarized in Table 5.1.

\subsection{Corticosteroids for Patients with Refractory Shock in Resource-Limited ICUs}

Sepsis and septic shock constitute major global health-care problems, particularly in resource-limited countries, where there is a large burden of infectious diseases, and are associated with significant morbidity and mortality [1, 10, 11]. Early and appropriate antimicrobial therapy, intravenous fluids, vasopressors, and source control were necessary, and appropriate supportive care comprises the fundamental principles of therapy in such cases $[1,10]$.

Several adjunctive therapies for septic shock have been developed and studied, and various treatment strategies evaluated, without improving outcomes [12-15]. Sepsis is associated with systemic inflammation, which may be a significant contributor to the 


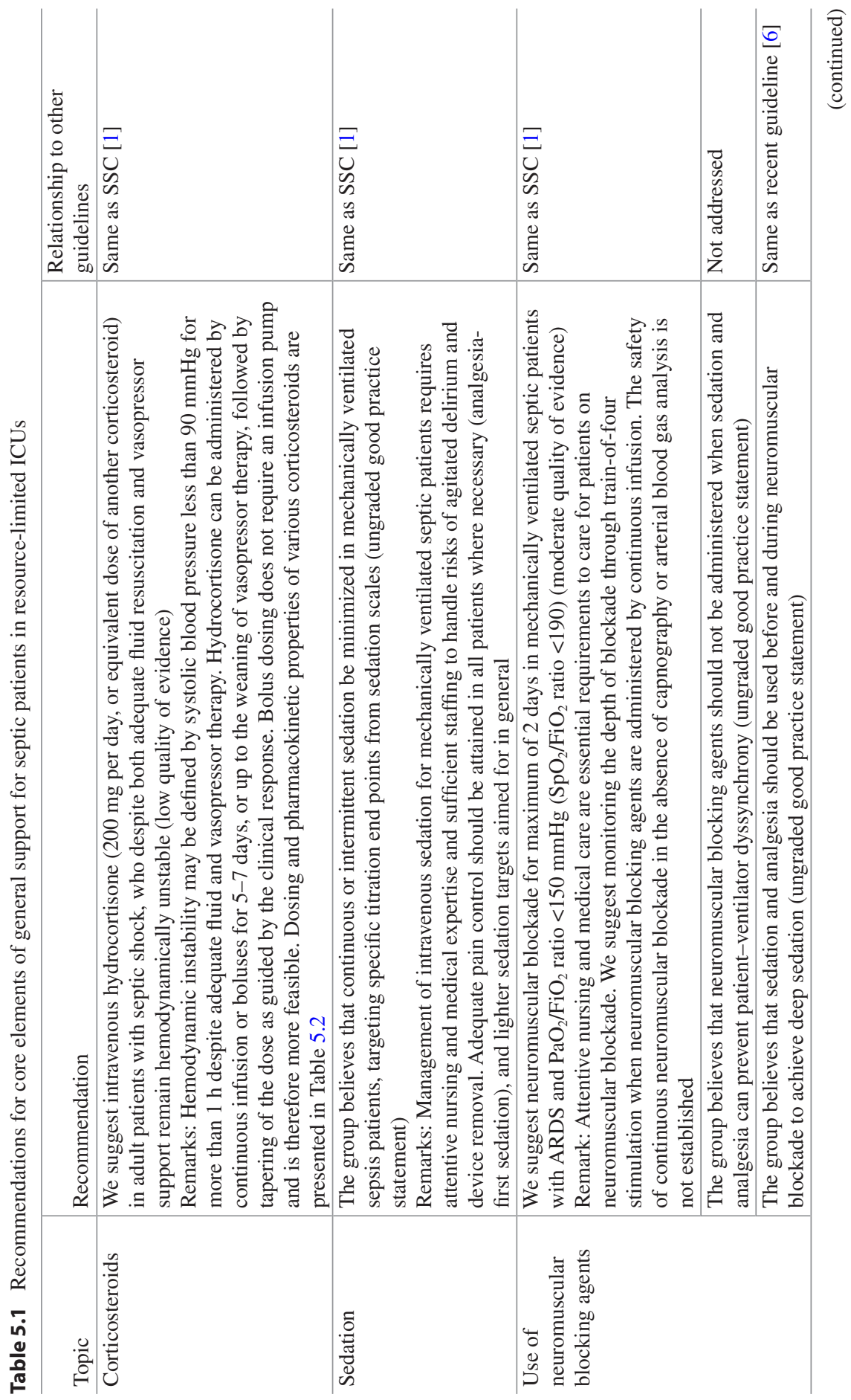




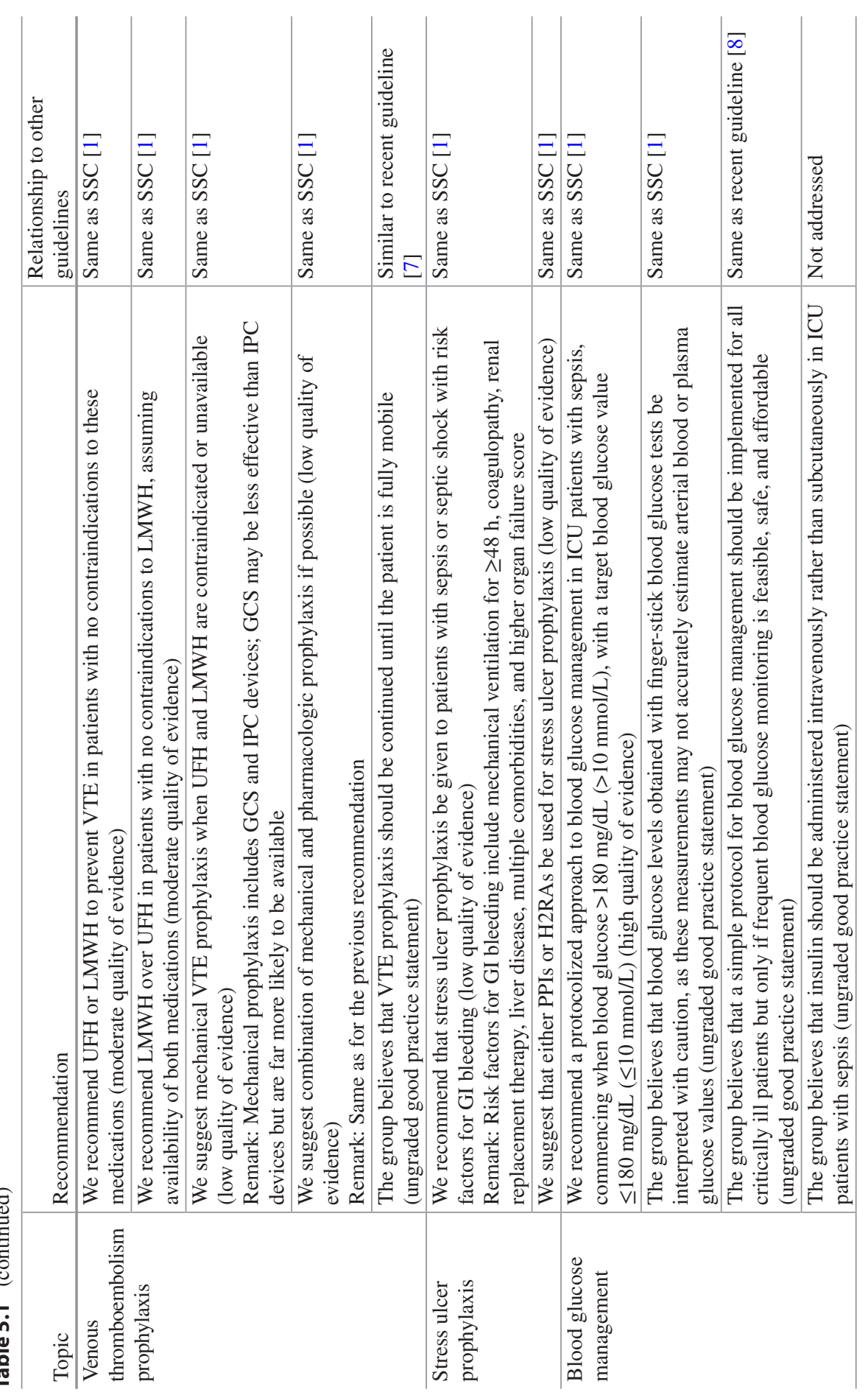




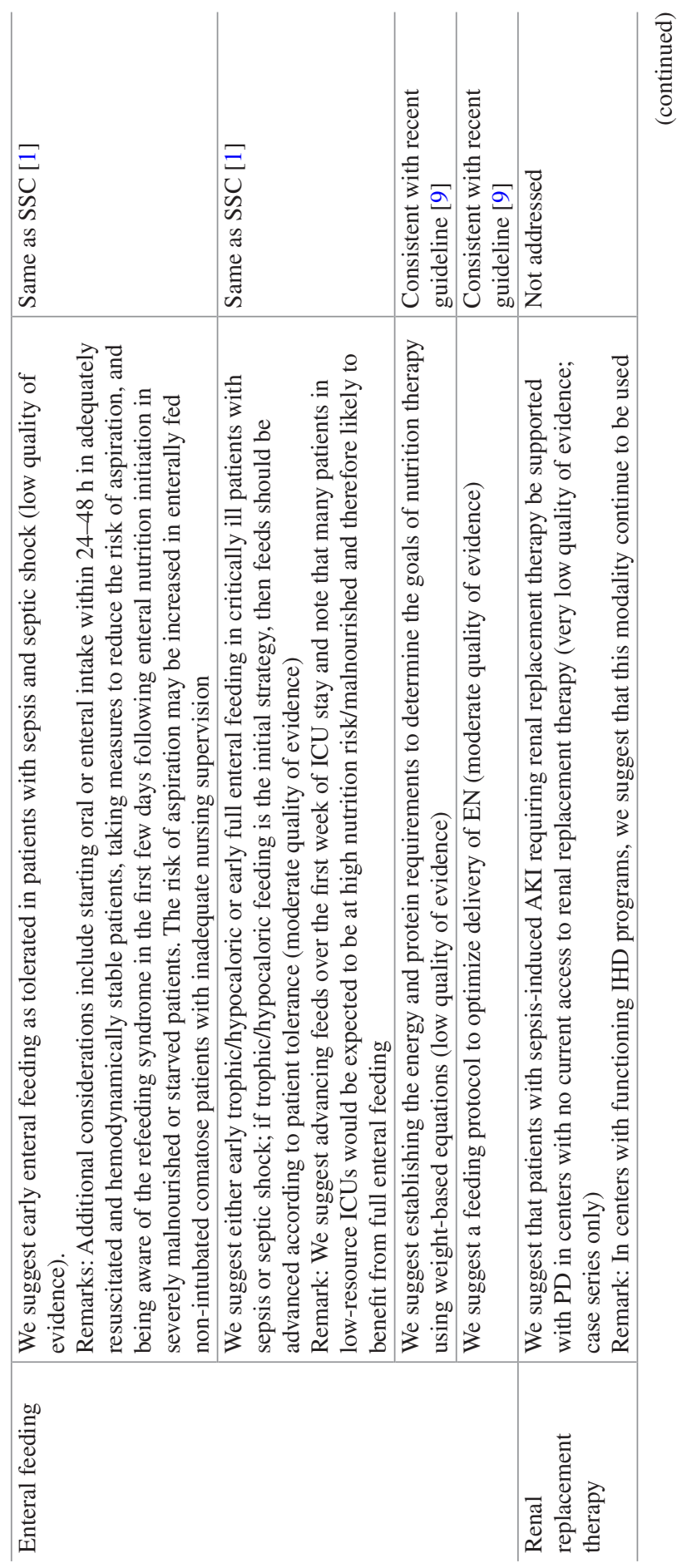




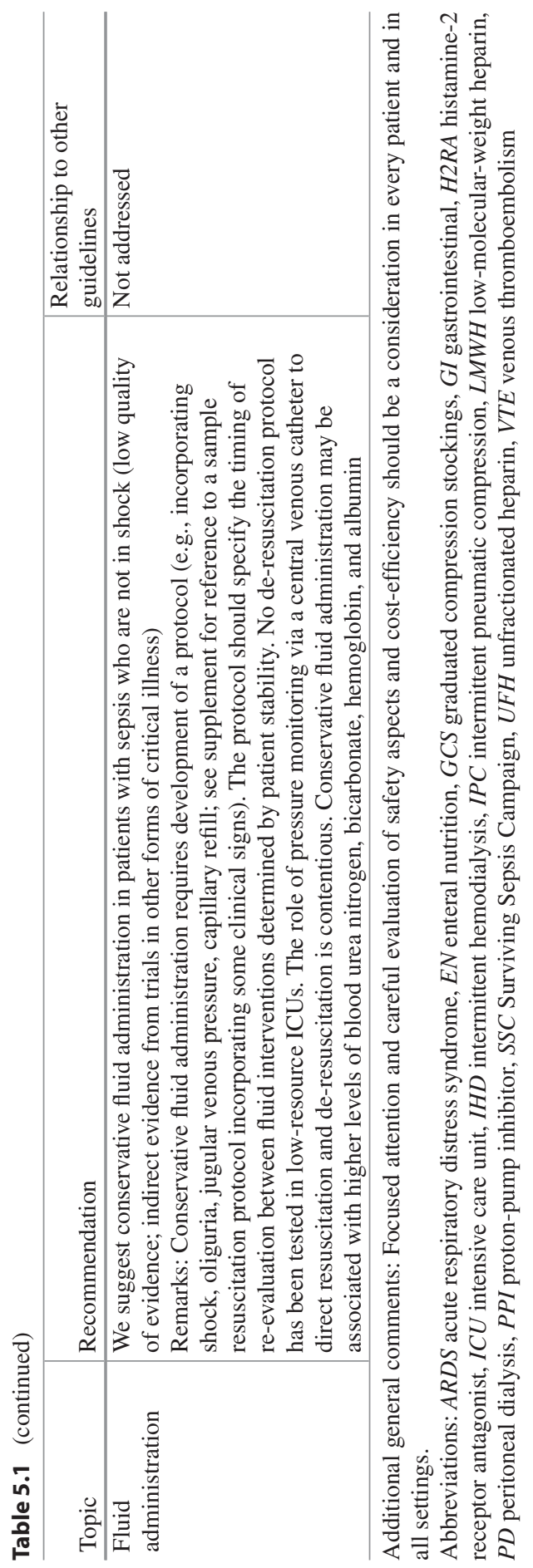


progression of organ dysfunction and death if uncontrolled [16-20]. Sepsis may also be complicated by impaired corticosteroid metabolism and hypothalamic-pituitaryadrenal axis (HPA) dysfunction in critically ill patients [21-25]. This HPA axis dysfunction in critically ill patients has been referred to as critical illness-related corticosteroid insufficiency (CIRCI) and relates to inadequate corticosteroid activity for the severity of illness as a consequence of decreased adrenal corticosteroid production, as well as tissue resistance to corticosteroids. The process is a dynamic one and may be reversible.

Proinflammatory cytokines and structural damage to the adrenal glands have been implicated in the etiology $[17,18]$. The terms "relative" adrenal insufficiency and "functional" adrenal insufficiency have also been used to allude to the same entity [26]. Based on the recognition of the role of excessive inflammation and impaired corticosteroid metabolism in the pathophysiology of multisystem organ dysfunction, corticosteroids have been extensively studied as adjunctive therapy in patients with septic shock over several decades [10, 20, 27-29]. Corticosteroids have the ability to modulate the inflammatory response. They reduce inflammation by decreasing cytokines, adhesion molecules, and other mediators. Corticosteroids halt the activation of various transcription factors and inhibit nuclear factor kappa beta (NF- $\mathrm{KB})$, which plays a crucial role in cytokine gene transcription, thereby ameliorating inflammation [18, 20, 30-33]. Additionally, corticosteroids are proapoptotic, assist in maintaining vascular tone by reversing depressed vasopressor sensitivity to catecholamines, maintain endothelium integrity and myocardial contractility, and have an effect on the coagulation cascade by inhibiting platelet aggregation and attenuating tissue factor-mediated activity [20, 34-36].

More recently, the concept of relative adrenal insufficiency as well as of CIRCI has been challenged. This has been based on altered cortisol metabolism in critically ill patients. An increase in cortisol production by a corticotropin-independent mechanism, probably cytokine mediated, and a decrease in cortisol clearance that together contribute to hypercortisolemia and corticotropin suppression have been described [22, 37]. Patients with high cortisol levels have also been shown to have less favorable outcomes $[38,39]$, which has raised concern about the safety of exogenous administration. Additionally, currently used methods for cortisol measurement have poor agreement, and it has been suggested that the corticotropin stimulation test may not be a valid marker for adrenal dysfunction [40-42].

The use of corticosteroids in the setting of septic shock has been the subject of controversy and uncertainty [1, 19, 43-48]. Initial studies of adjunctive high-dose corticosteroid therapy in patients with septic shock found no evidence of survival benefit $[49,50]$. More recent randomized controlled trials (referred to hereafter as "trials") and systematic reviews have suggested that low-dose corticosteroids of longer duration may benefit patients in terms of shock reversal, length of ICU stay, and mortality, with limited adverse effects [1, 19, 28, 29, 47, 51-53]. Adjunctive corticosteroid therapy has been used in a wide array of life-threatening infectious diseases with reported beneficial effects [54-67].

A search of MEDLINE and of references from relevant reviews did not produce any trials that directly addressed the question posed. The search did identify two 
papers on recommendations for sepsis management in resource-limited settings where some aspects of corticosteroid therapy in refractory shock in resource-limited settings are addressed [2, 68]. A sepsis guideline for Pakistan was also identified, which addressed aspects of corticosteroid administration in patients with sepsis should hemodynamic targets not be met with fluid resuscitation and vasopressor support [69]. Several studies and guidelines from resource-rich ICUs were identified and are included in the discussion.

Trials conducted in the 1980s with high-dose corticosteroids in patients with septic shock failed to demonstrate a mortality benefit, although decreased time to shock reversal was noted in one trial $[49,50,70,71]$. With the abandonment of the use of high-dose corticosteroids in septic shock, the focus of attention shifted to the concept of relative adrenal insufficiency in septic shock and the use of lower doses of corticosteroids. Promising data emerged using lower doses of corticosteroids (socalled supra-physiological or stress doses of hydrocortisone, 200-300 mg/day), with reports of shock reversal, trends toward earlier resolution of organ dysfunction, and improved mortality $[52,53]$. A multicenter trial $(n=300)$ appeared to demonstrate improved 28-day survival in patients with vasopressor-refractory septic shock and relative adrenal insufficiency who were given low-dose intravenous hydrocortisone (50 mg every $6 \mathrm{~h}$ ) and low-dose fludrocortisone for 7 days [51]. Study patients were hypotensive despite intravenous fluid and vasopressor administration; the benefit was only seen in nonresponders to an adrenocorticotrophic hormone (ACTH) test (blood cortisol level failed to rise appropriately in response to a dose of synthetic ACTH) (hydrocortisone vs. placebo mortality 53\% vs. 63\%; $p=0.02$ using survival analysis but not significant in unadjusted chi-square test). Two subsequent meta-analyses found that longer courses (at least 5 days) of low-dose corticosteroids (hydrocortisone $200-300 \mathrm{mg} /$ day) were associated with a decrease in mortality without any significant increase in complications [72]. Based on the available data, the 2004 Surviving Sepsis Campaign guidelines recommended low-dose hydrocortisone in vasopressor-dependent septic shock following appropriate fluid resuscitation [73].

The subsequent Corticosteroid Therapy of Septic Shock (CORTICUS) trial randomized 499 patients with septic shock to receive low-dose intravenous hydrocortisone (50 mg every $6 \mathrm{~h}$ ) or placebo [74]. The study showed faster shock reversal but no mortality benefit with corticosteroids (hydrocortisone vs. placebo $34.3 \%$ vs. $31.5 \% ; p=0.51$ ). The study enrolled all patients with septic shock, including those who did not respond to vasopressors, and the use of the ACTH test did not predict benefit. Corticosteroid administration was associated with an increased incidence of superinfection and new sepsis but was not associated with an increased incidence of polyneuropathy. Various authors have pointed out differences between CORTICUS and the earlier trial [51]: patients in CORTICUS had a much lower severity of illness, could be enrolled for up to $72 \mathrm{~h}$ after the onset of shock (vs. $8 \mathrm{~h}$ ), and were given hydrocortisone for a lesser duration, which may have reduced the potential benefits. Additionally, in the years between the studies, improved management with sepsis bundles and new guidelines may also have reduced corticosteroid benefits. A post hoc subgroup analysis of CORTICUS patients who met the 
inclusion criteria used in the earlier trial [51] showed a lower 28-day mortality with hydrocortisone $[18,44,75,76]$. Finally, fludrocortisone was not used in CORTICUS, but a subsequent trial involving 509 patients with septic shock randomized to receive hydrocortisone plus fludrocortisone or hydrocortisone alone later negated its potential benefit (Corticosteroids and Intensive Insulin Therapy for Septic Shock (COIITSS) trial) [77].

The 2008 Surviving Sepsis Campaign guidelines suggested that low-dose hydrocortisone only be given to patients who respond poorly to intravenous fluids and vasopressors and that an ACTH test was not necessary [78]. A different consensus statement by an international task force recommended that low-dose hydrocortisone should be considered in the management of patients with septic shock, especially those who have responded poorly to fluid resuscitation and vasopressors. Intravenous hydrocortisone in a dose of $200 \mathrm{mg} / \mathrm{day}$ in four divided doses, or as a bolus of $100 \mathrm{mg}$ followed by a continuous infusion of $10 \mathrm{mg} / \mathrm{h}$, was recommended. The task force suggested continuation for 5-7 days before tapering (rather than abrupt cessation), assuming no recurrence or sepsis or septic shock. They also suggested that tests of adrenal function were not routinely required [17]. A systematic review of corticosteroids in the treatment of sepsis and septic shock involving 17 randomized trials and 3 quasi-randomized trials with acceptable methodological quality suggested beneficial drug effects on shock reversal and 28-day mortality, without increasing the risk of gastroduodenal bleeding, superinfection, or neuromuscular weakness. Corticosteroids were, however, associated with an increased risk of hyperglycemia and hypernatremia [79]. Another systematic review suggested no increased risk of superinfection in patients treated with corticosteroids for septic shock and that corticosteroids significantly reduced the incidence of vasopressordependent septic shock [80]. Various reviews and commentaries on the topic have advocated the use of low doses of corticosteroids in refractory septic shock [18, 19, $44,47,81]$.

The 2012 Surviving Sepsis Campaign guidelines suggested $200 \mathrm{mg} /$ day of hydrocortisone to treat patients with septic shock if adequate fluid resuscitation and vasopressor therapy are unable to restore hemodynamic stability (grade 2B). The guidelines recommend against the use of an ACTH stimulation test to identify patients with septic shock who should receive corticosteroid therapy. The guidelines also recommend against the use of corticosteroids to treat sepsis in the absence of shock (grade 1D). Tapering of the administered hydrocortisone is suggested, as is the use of a continuous infusion hydrocortisone (grade 2D) [1]. The 2016 Surviving Sepsis guidelines restated the first recommendation (weak recommendation, low quality of evidence), but did not issue recommendations on the ACTH test, tapering schedule, or continuous vs. intermittent administration.

The timing of corticosteroid therapy was addressed in a retrospective observational study involving 178 critically ill patients with septic shock. Early initiation of low-dose corticosteroids (within $6 \mathrm{~h}$ after the onset of septic shock) was associated with a significant $37 \%$ reduction in mortality [28]. Another retrospective, multicenter, propensity-matched cohort study involving patients with septic shock who received intravenous low-dose corticosteroid therapy within $48 \mathrm{~h}$ of diagnosis of 
septic shock revealed a beneficial effect on mortality only in patients with the highest severity of illness [45]. In general, data from observational studies on corticosteroids for septic shock have been conflicting, with many studies finding no benefit [45, 82-84] or harm [85, 86].

Recommendations addressing sepsis management in resource-limited settings have advocated the administration of intravenous hydrocortisone (up to $300 \mathrm{mg}$ / day) or prednisolone (up to $75 \mathrm{mg} /$ day) to adult patients requiring escalating dosages of vasopressor support [2]. Additional recommendations include not exceeding $300 \mathrm{mg}$ hydrocortisone or $75 \mathrm{mg}$ prednisolone (to mitigate the risk of additional infections), not administering corticosteroids to patients not requiring vasopressor support unless they are on chronic corticosteroid therapy, and, when vasopressor support is withdrawn, to slowly taper corticosteroids over several days to avoid rebound hypotension. A similar approach has been suggested in another paper addressing the management of sepsis with limited resources [68]. The Sepsis Guidelines for Pakistan, endorsed by the Global Sepsis Alliance, recommends the administration of intravenous hydrocortisone (50 mg every $6 \mathrm{~h}$ ) should hemodynamic targets not be met following adequate fluid resuscitation and where dose requirements of vasopressors rapidly escalate [69].

A most recent Cochrane systematic review and meta-analysis has evaluated both the rationale and current evidence from 33 randomized trials involving 4268 patients with respect to corticosteroids in septic shock [29]. Corticosteroids reduced 28-day mortality by $13 \%$, significantly decreased the length of ICU and hospital stay, decreased organ dysfunction and failure, and increased the proportion of shock reversal by day 7 by $31 \%$. Length of stay in the ICU was reduced by more than 2 days. Survival benefits were dependent on lower doses of corticosteroids (less than $400 \mathrm{mg}$ of hydrocortisone or equivalent) given for a longer duration of treatment ( 3 or more days at the full dose). The review also suggested that the sickest patients with sepsis were more likely to derive benefit from corticosteroids. The administration of low-dose corticosteroids was not found to be associated with gastrointestinal bleeding, superinfection, or neuromuscular weakness. In some studies, corticosteroids were associated with mild increases in blood glucose and sodium levels.

Further information will become available after publication of two large trials [87, 88] (planned $n=3800$ and 1241, respectively), both of which will investigate hydrocortisone ( $200 \mathrm{mg} /$ day) versus placebo in patients with septic shock; the second trial will also study fludrocortisone.

Corticosteroids given in low-dose are readily available and inexpensive, and evidence exists to support their use in septic patients with refractory shock; various formulations are on the World Health Organization's Essential Medicines List [89]. Data from recent systematic reviews suggest no increased risk of gastrointestinal bleeding, superinfection, or neuromuscular weakness. Their use may, however, be associated with an increased risk of hyperglycemia and hypernatremia.

After reviewing the evidence (no additional trials from resource-limited ICUs) and considering availability, feasibility, affordability, and safety, our recommendation and grading are consistent with the Surviving Sepsis guidelines. We suggest 
Table 5.2 Characteristics of corticosteroids

\begin{tabular}{l|l|l|l}
\hline Type & $\begin{array}{l}\text { Equivalent } \\
\text { anti-inflammatory } \\
\text { doses (potency) }\end{array}$ & $\begin{array}{l}\text { Mineralocorticoid } \\
\text { potency }\end{array}$ & $\begin{array}{l}\text { Biological } \\
\text { half-life } \\
\text { (hours) }\end{array}$ \\
\hline Hydrocortisone & $20 \mathrm{mg}(1)$ & 1.0 & $8-12$ \\
\hline Cortisone & $25 \mathrm{mg}(0.8)$ & 0.8 & $8-12$ \\
\hline Prednisolone/prednisone & $5 \mathrm{mg}(4)$ & 0.8 & $12-36$ \\
\hline Methylprednisolone & $4 \mathrm{mg}(5)$ & 0.5 & $12-36$ \\
\hline Dexamethasone & $0.75(25)$ & 0 & $36-54$ \\
\hline Fludrocortisone & - & 125 & $18-36$ \\
\hline
\end{tabular}

Adapted from [268-270]

intravenous hydrocortisone (200 mg per day, or equivalent dose of another corticosteroid) in adult patients with septic shock, who despite both adequate fluid resuscitation and vasopressor support remain hemodynamically unstable (low quality of evidence). Of note, hemodynamic instability may be defined by systolic blood pressure $<90 \mathrm{mmHg}$ for $>1 \mathrm{~h}$. Hydrocortisone can be administered by continuous infusion or boluses for 5-7 days, or up to the weaning of vasopressor therapy, followed by tapering of the dose as guided by the clinical response. Bolus dosing does not require an infusion pump and is therefore more feasible. Dosing and pharmacokinetic properties of various corticosteroids are presented in Table 5.2.

\subsection{Sedation for Patients with Sepsis in Resource-Limited ICUs}

Sedation has been a feature of intensive care since the inception of mechanical ventilation. The earliest ventilators had only mandatory modes, followed by ventilators with insensitive triggers that made patient-ventilator synchronization a challenge. Deep sedation was the pragmatic solution for this problem. Progress in technology and the development of sensitive ventilator trigger outpaced widespread adaptation in sedation practice, despite emerging evidence for the detrimental effects of sedation and specifically deep sedation.

Sedation, especially when deep, has been associated with risk of increased organ dysfunction [90, 91], delirium, cognitive deficit, increased length of stay (LOS) in ICU and hospital, and increased mortality [92]. Strategies to decrease the risk of oversedation include the use of sedation protocols to lighter sedation targets, daily sedation interruptions, or no sedation. Bolus dosing of sedatives is another strategy to titrate sedation to a specified target and prevent oversedation.

A MEDLINE search found no trials that address this question in resource-limited ICUs. The search and references from relevant reviews did not produce any trials that directly addressed the question posed. The 2016 Surviving Sepsis guidelines made a best practice recommendation that continuous or intermittent sedation be minimized in mechanically ventilated sepsis patients, targeting specific titration end points. Earlier comprehensive guidelines [19] on pain, agitation, and delirium 
recommend that sedative medications be titrated to maintain a light rather than a deep level of sedation in adult ICU patients, unless clinically contraindicated. Neither guideline makes a recommendation about continuous or bolus dosing.

In a single-center prospective observational study [93] of 142 consecutive mechanically ventilated ICU patients, 38.4\% received continuous IV sedation (mostly lorazepam [72\%] and fentanyl [71\%]) to achieve a Ramsay score of 3. A majority $(61.6 \%)$ received either bolus sedation $(n=64)$ or no intravenous sedation after intubation $(n=85)$. Patients with continuous IV sedation spent more time on mechanical ventilation (by $130 \mathrm{~h}$ ) and had longer ICU LOS (by 8.7 days) hospital LOS (by 8.2 days; all adjusted $p \leq 0.007$ ). There were no statistically significant differences in mortality, time of mechanical ventilation ( 68.5 vs. $45.9 \mathrm{~h}, p=0.07)$, or hospital LOS (14.8 vs. 11.3 days, $p=0.127$ ) between patients receiving bolus sedation vs. no sedation but a longer ICU LOS (5.7 vs. 4.1 days, $p=0.017$ ).

A single-center randomized controlled trial [94] randomized 321 patients to protocol-directed vs. non-protocol-directed sedation and found lower duration of mechanical ventilation (mean 89.1 vs. $124.0 \mathrm{~h}, p=0.003$ ), lower LOS in ICU (mean 5.7 vs. 7.5 days, $p=0.013$ ) and hospital (mean 14.0 vs. 19.9 days, $p<0.001)$, and lower tracheostomy rate $(6.2 \%$ vs. $13.2 \%, p=0.038)$. In the subgroup of patients who received continuous intravenous sedation $(n=132,41.1 \%$ of total), the protocol-directed sedation group had a significantly shorter duration of continuous intravenous sedation ( 3.5 vs. 5.6 days, $p=0.003$ ). A Cochrane systematic review ( 2 trials, $n=633$ ) [95] found no differences between patients managed with protocol-directed sedation vs. usual care in efficacy outcomes or adverse events (unplanned extubation or reintubation), but the results of the two included trials conflicted.

Kress et al. [96] randomized 128 patients in a single-center randomized controlled trial to an intervention group sedation with target Ramsay score of 3-4 and daily interruption of continuous sedative infusions. The control group received standard care with no-sedation target or interruption of sedation. Duration of mechanical ventilation and ICU LOS were reduced by 2.4 days $(p=0.004)$ and 3.5 days $(p=0.02)$ in the intervention group, respectively, with no difference in the risk of self-extubation. Subsequent analysis showed fewer complications in the intervention group (2.8\% vs. 6.2\% in control group, $p=0.04$ ) [97] and no increase in the risk of myocardial ischemia [98]. However, a larger multicenter trial $(n=430)$ showed no effect of daily sedation interruption when both groups were managed with a sedation protocol; patients in the daily interruption group received higher doses of benzodiazepines and opiates. A Cochrane systematic review on daily interruption of sedation [99] did not find strong evidence in favor of this approach, although point estimates for efficacy outcomes favored the intervention and a post hoc subgroup analysis of five trials conducted in North America did show reduced duration of mechanical ventilation. There were no differences in risks of unplanned extubation or catheter removal.

Concerns about patient emotional and physical discomfort were raised in a prospective observational study (31 Chinese academic ICUs, $n=163$ ). The majority 
$(79.1 \%)$ of patients remembered seriously uncomfortable experiences; protocolized sedation or non-protocolized continuous sedation but not intermittent sedation reduced the risk of complex-mixed discomfort episodes. Of note, 37.4\% of patients did not receive any sedation, and only $14.7 \%$ received protocolized sedation. The nurse-patient ratio was not stated [100]. Overall, traditional concerns that light sedation or sedation interruptions are associated with worse psychological outcomes seem to be unfounded. Lightly sedated or non-sedated patients may do better than deeply sedated patients [91, 101-103].

To investigate a more extreme version of light sedation, Strom et al. [91] randomized 140 critically ill adults in one center with expected mechanical ventilation $>24 \mathrm{~h}$ to receive either continuous sedation with propofol for $48 \mathrm{~h}$ and lorazepam thereafter, with daily sedation interruptions $(n=70)$, or no sedation $(n=70)$. Both groups received bolus doses of morphine ( $2.5 \mathrm{or} 5 \mathrm{mg}$ ) as needed, and the no-sedation group could receive boluses of haloperidol for delirium. The no-sedation group has improvements in ventilator-free days to day 28 and ICU and hospital LOS, but patients who died or who were extubated within $48 \mathrm{~h}$ were excluded, and hence the analysis did not include all randomized patients. The no-sedation group also experienced more agitated delirium, and 10/58 patients crossed over to the sedation group. The nurse-patient ratio was 1:1; the no-sedation group needed an additional member of staff on 11 vs. 3 occasions for the sedation group, corresponding to 2.5 days of extra staff time.

Relevant considerations include the following: (1) morphine, midazolam, and diazepam are generic medications and on the World Health Organization's Essential Medicines List [89], although in practice they may not be uniformly available; (2) care of the mechanically ventilated patient with sepsis requires attentive nursing and medical expertise, including the administration and monitoring of intravenous sedation; and (3) depending on staffing models, medical attendance to a patient who self-extubates and requires reintubation may be delayed, particularly outside of weekday daytime hours. Diazepam may be particularly challenging to use because of its active metabolites and long half-life. Systematic reviews have not documented an increased risk of device removal with "light" sedation approaches [95, 99]. Existing literature from high-income countries derives from ICUs with one nurse per one to two patients. These issues point to the need for caution in managing sedation needs in low-resource ICUs, many of which have less nursing staffing.

After reviewing the evidence (no additional trials from low-resource ICUs) and considering availability, feasibility, affordability, and safety, our recommendation and grading are consistent with the Surviving Sepsis guidelines. The group believes that continuous or intermittent sedation be minimized in mechanically ventilated sepsis patients, targeting specific titration end points (ungraded good practice statement).

Of note, management of intravenous sedation for mechanically ventilated septic patients requires attentive nursing and medical expertise and sufficient staffing to handle risks of agitated delirium and device removal. There are no trials of continuous vs. bolus sedation dosing in resource-limited settings. 


\subsection{Neuromuscular Blocking Agents for Mechanical Ventilation}

The role of neuromuscular blocking agents in the ICU is undefined, and there is no clear evidence that neuromuscular blockade in septic mechanically ventilated patients reduces mortality or morbidity. Nevertheless, neuromuscular blocking agents are often administered to critically ill patients to prevent patient-ventilator dyssynchrony [104], a strategy that anecdotally may be practiced more frequently in resource-limited ICUs than in resource-rich settings. Other indications for neuromuscular blockade are to reduce peak airway pressures and to improve chest wall compliance [104] and to reduce oxygen consumption by decreasing the work of breathing and respiratory muscle blood flow [105].

The MEDLINE search did not result in any study from resource-limited ICUs that directly answered the question of interest. We discuss several studies from resource-rich ICUs. The 2016 Surviving Sepsis guidelines suggest using neuromuscular blockers for $\leq 48 \mathrm{~h}$ in adults with sepsis-induced acute respiratory distress syndrome (ARDS) and a $\mathrm{PaO}_{2} / \mathrm{FiO}_{2}$ ratio $<150 \mathrm{mmHg}$ (weak recommendation, moderate quality of evidence). One recent systematic review [106] of three trials (all from France) in patients with ARDS showed improved survival, more ventilatorfree days at day 28, higher $\mathrm{PaO}_{2} / \mathrm{FiO}_{2}$ ratio, and less barotrauma with continuous infusions of the neuromuscular blocking agent cisatracurium for 2 days compared to standard care [107-109]. Most patients in these three trials met criteria for sepsis. The incidence of ICU-acquired weakness was not affected. Several previous observational studies have found an association of neuromuscular blockade with weakness in patients with severe asthma [110-112], although this signal has not been uniform [113, 114]. Several areas of uncertainly remain. First, peripheral nerve monitoring of the depth of neuromuscular blockade (i.e., train-of-four [TOF] stimulation) was only performed in the two smaller trials $[107,108]$. Current guidelines [6] suggest that TOF may be useful for monitoring depth blockade but only if incorporated with clinical assessment and suggest that TOF may not be used alone for this purpose. Second, it is uncertain whether a neuromuscular blocking agent other than cisatracurium would have similar effects. Further information about the effects of neuromuscular blockade in the acute respiratory distress syndrome will be available after completion of a large ongoing trial [115].

Selected neuromuscular blocking agents (albeit not cisatracurium) are on the World Health Organization's Essential Medicines List [89] and should therefore be available in resource-limited settings, although in practice they may not be uniformly available. Even if available, associated costs can be substantial when given in a continuous fashion, as this delivery method increases the amount given and requires a syringe pump. The literature is conflicting regarding the benefits of TOF monitoring over clinical judgment to guide administration of neuromuscular blockers [116-118], with only a weak recommendation in favor [6], but it may reduce the amounts given, leading to faster recovery of neuromuscular function, shorter duration of intubation, and lower costs. On the other hand, costs of TOF meters could minimize any financial benefit of neuromuscular blockade. Attentive nursing and 
medical care are required to care for patients on neuromuscular blockade, with current guidelines suggesting structured physiotherapy and glucose control (to $<180 \mathrm{mg} / \mathrm{dL},<10 \mathrm{mmol} / \mathrm{L}$ ) for these patients [6]. The safety of continuous neuromuscular blockade in the absence of capnography or arterial blood gas analysis is not established.

After reviewing the evidence (no additional trials from low-resource ICUs) and considering availability, feasibility, affordability, and safety, our first recommendation and grading are consistent with the Surviving Sepsis guidelines. We suggest neuromuscular blockade for a maximum of 2 days in mechanically ventilated septic patients with ARDS and $\mathrm{PaO}_{2} / \mathrm{FiO}_{2}$ ratio $<150 \mathrm{mmHg}\left(\mathrm{SpO}_{2} / \mathrm{FiO}_{2}\right.$ ratio $\left.<190\right)$ (moderate quality of evidence). Of note, attentive nursing and medical care are essential requirements to care for patients on neuromuscular blockade. We suggest monitoring the depth of blockade through TOF stimulation when neuromuscular blocking agents are administered by continuous infusion. The safety of continuous neuromuscular blockade in the absence of capnography or arterial blood gas analysis is not established. The conversion of $\mathrm{PaO}_{2} / \mathrm{FiO}_{2}$ ratio to $\mathrm{SpO}_{2} / \mathrm{FiO}_{2}$ ratio is from reference [119].

The group believes that neuromuscular blocking agents should not be administered when sedation and analgesia can prevent patient-ventilator dyssynchrony (ungraded good practice statement). The group believes that sedation and analgesia should be used before and during neuromuscular blockade to achieve suitable sedation (ungraded good practice statement). This statement is consistent with recent guidelines [6].

\subsection{Deep Venous Thrombosis Prophylaxis in Resource-Limited ICUs}

Venous thromboembolism (VTE) is a common and severe complication of critical illness and includes the entities of deep venous thrombosis and pulmonary embolism [120, 121]. VTE is recognized as being the commonest preventable cause of hospital death in resource-rich settings, and evidence strongly supports the value of VTE prophylaxis $[122,123]$. Guidelines of many scientific societies strongly recommend that every hospital should have a policy for VTE prophylaxis $[122,123]$.

Sepsis has been demonstrated to be an independent risk factor for the development of VTE in critically ill patients [7, 120, 124-127]. Therapeutic modalities involved in the management of septic critically ill patients may further contribute to the risk, including mechanical ventilation, central venous catheters, and vasopressors. The inflammatory milieu of sepsis is felt to play an important role in the pathogenesis of VTE [127-130]. Patients with certain forms of infections, such as HIV/ AIDS and tuberculosis (TB), which are commonly seen in resource-limited environments, have been shown to be at particularly high risk for VTE [7, 131-135].

An association between mortality and lack of prophylaxis in ICU patients has been demonstrated in both resource-rich and resource-limited settings [136-138]. 
Data from developing countries, however, has revealed a significant underutilization of VTE prophylaxis [138, 139].

The MEDLINE search did not produce any trials that directly answered this question in resource-limited settings. Several relevant guidelines, recommendations, commentaries, overviews, and studies of VTE prophylaxis were identified, in addition to one retrospective cohort of patients with VTE [140].

The 2016 Surviving Sepsis guidelines [1] make two strong recommendations (moderate quality of evidence): pharmacologic prophylaxis (unfractionated heparin [UFH] or low-molecular-weight heparin [LMWH]) against venous thromboembolism (VTE) in the absence of contraindications to the use of these agents and LMWH rather than UFH for VTE prophylaxis in the absence of contraindications to the use of LMWH. The guidelines also make two weak recommendations (low quality of evidence): combination pharmacologic VTE prophylaxis and mechanical prophylaxis, whenever possible, and mechanical VTE prophylaxis when pharmacologic VTE is contraindicated.

Sepsis guidelines for Pakistan recommend daily pharmacologic prophylaxis (UFH twice daily or LMWH, depending on hospital policy and environment), with intermittent pneumatic compression (IPC) in the case of coagulopathy or low platelets. Where IPC is not available, graduated compression stockings (GCS) are advocated [69]. The South African Guideline on venous thromboembolism recommends pharmacologic prophylaxis with UFH (three times per day) or LMWH until the patient is fully mobile and states that evidence-based data show LMWH to be superior to UFH. Mechanical prophylaxis (GCS or IPC) is suggested as an alternative for patients at high risk of bleeding [7].

VTE prophylaxis has been shown to be effective in a plethora of trials in various populations of acutely ill patients [141-147]. At least two well-conducted systematic reviews further corroborate the efficacy of VTE prophylaxis [148, 149]. Many of the patients studied in these trials had sepsis. The Surviving Sepsis Campaign guidelines and the American College of Chest Physicians guidelines both strongly recommend VTE prophylaxis in the absence of contraindications [1, 123]. Similarly, VTE prophylaxis is advocated in various guidelines, overviews, and commentaries addressing resource-limited settings [2, 124, 138].

Studies have shown that the practice of VTE prophylaxis is suboptimal globally $[150,151]$. VTE underutilization, nonadherence to guidelines, and lack of awareness of risk factors have been documented in resource-limited settings [137-139, 152-154]. For example, in an observational study from India, 100\% of ICU patients were assessed as being at highest risk for VTE [138]. Just over 25\% deemed to be at the highest risk for VTE had sepsis or bloodstream infection; only $11 \%$ of the highest risk patients received VTE prophylaxis. VTE has also been documented to be a common finding at autopsy, with many patients noted to be young [155] and to have had septic shock [156].

Guideline adherence and VTE risk stratification are often lacking in resourcelimited settings. In a cross-sectional descriptive study conducted in a tertiary care hospital in Nigeria, almost three-fourth of physicians did not perform VTE risk assessment of patients, and only $18.8 \%$ follow guidelines on VTE prophylaxis 
[157]. Similar data regarding low level of awareness of VTE risk factors has been reported in a national cross-sectional study from Mexico [158]. In an overview of strategies to reduce mortality from bacterial sepsis in adults in developing countries, the authors point out that VTE prophylaxes are both warranted and available in most resource-limited settings [55].

Recently, a prospective multicenter study $(n=113)$ from a high-resource setting [127] found a three- to tenfold higher incidence of VTE in patients admitted with sepsis and septic shock compared to published reports in primarily non-septic ICU patients. The incidence of VTE was $37.2 \%$, and the majority of emboli (88\%) were clinically significant pulmonary emboli or DVT. Patients with VTE had a statistically significant increased length of hospital stay of approximately 5 days. Insertion of a central venous catheter and longer duration of mechanical ventilation were additional risk factors. The higher incidence of VTE in this cohort occurred despite pharmacological prophylaxis, with the authors suggesting that higher doses of pharmacological prophylaxis or combination prophylaxis with both heparinoids and mechanical devices may be more effective in septic patients.

Prophylaxis involves both pharmacological and mechanical modalities; the former most frequently includes UFH or LMWH. A systematic review of seven trials ( $n=7226)$ of heparin prophylaxis in critically ill patients found that any heparin prophylaxis decreased VTE, with LMWH being superior to UFH for the outcome of pulmonary embolism. There was no effect of any heparin vs. placebo and no effect of LMWH vs. UFH on major bleeding [159]. A Cochrane systematic review of heparin (UFH or LMWH) in acutely ill medical patients (excluding stroke and myocardial infarction; 16 trials, $n=34,369$ ) revealed a significant reduction in VTE in patients who received any form of heparin prophylaxis. LMWH was superior to UFH and was associated with less major bleeding [160]. The PROTECT Investigators evaluated LMWH versus UFH in 3764 medical-surgical ICU patients and demonstrated no effect on proximal deep vein thrombosis but fewer pulmonary emboli in patients assigned to LMWH [161]. Pharmacological prophylaxis has been shown to be cost-effective for VTE prevention, with LMWH superior to UFH in an economic analysis of PROTECT [162, 163].

Mechanical measures include elastic GCS, IPC, and venous foot pumps. All these modalities have been shown to be beneficial in reducing VTE, likely by increasing venous blood flow and enhancing endogenous fibrinolysis [164]. A recent systematic review (70 trials, $n=16,164$ [165]) found that IPC reduced VTE compared to no IPC prophylaxis and GCS and had similar effect vs. pharmacological prophylaxis but with a reduced risk of bleeding. Adding pharmacological prophylaxis to IPC further reduced the risk of deep venous thrombosis vs. IPC alone.

Pharmacological prophylaxis is generally available in resource-limited ICUs and can be delivered feasibly and safely. The WHO Essential Medicines List includes both heparin and enoxaparin [89]. Mechanical modalities may not be available in many resource-limited ICUs but have the added potential advantage of being reuseable, which would lower costs.

After reviewing the evidence (no additional trials and one guideline from lowresource ICUs) and considering availability, feasibility, affordability, and safety, our 
recommendations and grading are consistent with the Surviving Sepsis guidelines, except when noted. We recommend UFH or LMWH to prevent VTE in patients with no contraindications to these medications (moderate quality of evidence). We recommend LMWH over UFH in patients with no contraindications to LMWH assuming availability of both medications (moderate quality of evidence). We suggest mechanical VTE prophylaxis when UFH and LMWH are contraindicated or unavailable (low quality of evidence). Of note, mechanical prophylaxis includes GCS and IPC devices; GCS may be less effective than IPC devices but are far more likely to be available. We suggest combination mechanical (IPC devices) and pharmacologic prophylaxis if possible (low quality of evidence). Of note, mechanical prophylaxis includes GCS and IPC devices; GCS may be less effective than IPC devices but are far more likely to be available. The group believes that VTE prophylaxis should be continued until the patient is fully mobile (ungraded good practice statement). This statement is consistent with that made in the South African VTE guideline [7].

\subsection{Stress Ulcer Prophylaxis in Patients with Sepsis in Resource-Limited ICUs}

Stress ulceration of the gastric mucosa in critically ill patients has been studied for many years, with mechanical ventilation for $\geq 48 \mathrm{~h}$ and presence of coagulopathy identified as risk factors [166]. A recent multicenter observational study conducted in 11 high-income countries found that clinically important gastrointestinal (GI) bleeding occurred in $2.6 \%$ (95\% CI 1.5-3.6\%) of patients [167]. In this study, independent risk factors for GI bleeding included $\geq 3$ comorbidities, liver disease, use of renal replacement therapy, coagulopathy, higher organ failure score, and use of acid suppressants at ICU admission (possibly due to confounding by indication). Systematic reviews of trials from mostly high-income countries have shown that either histamine-2 receptor antagonists (H2RAs) or proton-pump inhibitors (PPIs) reduce GI bleeding [168], with some evidence that PPIs are superior [169].

A MEDLINE search of recent literature (2012-2016) did not identify trials addressing this question. Previous systematic reviews [168, 169] included two trials (India) and five trials (Brazil, China, Iran, India) from middle-income countries, respectively.

The 2016 Surviving Sepsis guidelines [1] recommend, based on low quality of evidence, that stress ulcer prophylaxis be given to patients with sepsis or septic shock with risk factors for GI bleeding (strong recommendation) and suggest that either PPIs or H2RAs be used (weak recommendation). New data on the efficacy of stress ulcer prophylaxis will become available after ongoing trials of PPI vs. placebo are completed $[170,171]$.

Many H2RAs and PPIs are available as generic preparations and in principle should be widely available. Omeprazole and ranitidine (both in oral and injectable forms) are on the WHO Model List of Essential Medicines [89]. Systematic reviews of trials have not shown statistically significant differences in rates of pneumonia 
among PPIs, H2RAs, or control [168, 169]; trials have not addressed the comparative risk of $C$. difficile infection. Observational studies on the association between risk of $C$. difficile infection and stress ulcer prophylaxis with PPI have produced inconsistent results [172, 173].

After reviewing the evidence (no additional trials from low-resource ICUs) and considering availability, feasibility, affordability, and safety, our recommendations are consistent with the Surviving Sepsis guidelines. We recommend that stress ulcer prophylaxis be given to patients with sepsis or septic shock with risk factors for GI bleeding (low quality of evidence). Risk factors for GI bleeding include mechanical ventilation for $\geq 48 \mathrm{~h}$, coagulopathy, renal replacement therapy, liver disease, multiple comorbidities, and higher organ failure score. We suggest that either PPIs or H2RAs be used for stress ulcer prophylaxis (low quality of evidence).

\subsection{Glucose Control in Patients with Sepsis in Resource-Limited ICUs}

Dysglycemia frequently occurs in critically ill patients. Hyperglycemia may be associated with critical illness or less frequently due to diabetic ketoacidosis [174]. Certain infectious diseases, e.g., malaria, are associated with an increased risk of hypoglycemia, particularly in children and patients with limited glycogen stores, like malnourished patients or subjects with liver disease [175]. Hypoglycemia may also develop as a side effect of continuous insulin infusion for control of critical illness-associated hyperglycemia [176].

While early trials showed reduced mortality and morbidity with continuous intravenous administration of insulin aiming for normoglycemia $(80-110 \mathrm{mg} / \mathrm{dL}$, 4.4-6.1 mmol/L) in critically ill adult and pediatric patients [177, 178], subsequent trials of "intensive insulin therapy" suggested harm [176]. Also, almost without exception, "intensive insulin therapy" results in a much higher incidence of severe hypoglycemia $(<40 \mathrm{mg} / \mathrm{dL}, 2.2 \mathrm{mmol} / \mathrm{L})$ [176]. Consequently the international guidelines, including the Surviving Sepsis Campaign guidelines [1], moved from recommending "intensive insulin therapy" to recommending prevention of hyperglycemia (defined as $>180 \mathrm{mg} / \mathrm{dL},>10 \mathrm{mmol} / \mathrm{L}$ ). One of the five systematic reviews of "intensive insulin therapy" [179-183] showed "intensive insulin therapy" to be beneficial only in surgical ICU patients (risk ratio, 0.63 [0.44-0.9]) [180], but another review refuted this finding [181].

Blood glucose control with intravenous insulin is a very complex intervention, independent of the targets used [174, 176]. Many different protocols for the titration of intravenous insulin in ICU patients have been published [184]. It is unknown which of these protocols have been implemented in ICUs beyond the centers where they were designed, let alone whether they are effective and safe in other surroundings. It is generally considered important to guide the titration of intravenous insulin in ICU patients by frequent measurements of the blood glucose level [174], a strategy that is time- and blood-consuming and expensive. Also, it is advised to prefer bedside-based blood gas analyzers over finger-stick blood glucose tests, as accuracy 
of capillary blood glucose monitoring could be too low to guarantee safe and effective titration of intravenous insulin in ICU patients [176].

While insulin infusion is preferred over oral antihyperglycemic agents for blood glucose control in the ICU [174], a large variety of oral antihyperglycemic agents are available that may simplify and possibly improve blood glucose control in the ICU.

The MEDLINE search did not find trials of "intensive insulin therapy" from resource-limited ICUs. The search, however, identified one recent consensus guideline on blood glucose management in India [8] and three small Iranian trials of the oral antidiabetic agent, metformin [185-187]. Major issues of the Indian guideline are discussed, as are the results from the trials of metformin. We do not discuss the importance of preemptive treatment of hypoglycemia in patients with malaria but refer to another set of guidelines from our group, focusing on management of dengue and malaria [188].

The 2016 Surviving Sepsis guidelines [1] recommend a protocolized approach to blood glucose management in ICU patients with sepsis, commencing insulin dosing when two consecutive blood glucose levels are $>180 \mathrm{mg} / \mathrm{dL}$. This approach should target an upper blood glucose level $\leq 180 \mathrm{mg} / \mathrm{dL}$ rather than an upper target blood glucose level $\leq 110 \mathrm{mg} / \mathrm{dL}$ (strong recommendation, high quality of evidence). The guidelines suggest the use of arterial blood rather than capillary blood for point-ofcare testing using glucose meters if patients have arterial catheters (weak recommendation, low quality of evidence). The guidelines make two best practice statements: blood glucose values should be monitored every 1-2 h until glucose values and insulin infusion rates are stable and then every $4 \mathrm{~h}$ thereafter in patients receiving insulin infusions; glucose levels should be obtained with point-of-care testing of capillary blood be interpreted with caution because such measurements may not accurately estimate arterial blood or plasma glucose values.

Recently, a group of experts in the fields of diabetes and intensive care medicine from India framed recommendations regarding blood glucose control and monitoring for Indian ICUs [8]. One recommendation was to use a simple protocol for managing hyperglycemia for all critically ill patients, i.e., with no differences between various types of ICUs. The guideline recommended that the blood glucose target should be $140-180 \mathrm{mg} / \mathrm{dL}(7.8-10.0 \mathrm{mmol} / \mathrm{L})$ in critically ill patients but lower $(110-140 \mathrm{mg} / \mathrm{dL}, 6.1-7.8 \mathrm{mmol} / \mathrm{L})$ in patients after coronary bypass or uncomplicated surgery; blood glucose target values $<110 \mathrm{mg} / \mathrm{dL}(>6.0 \mathrm{mmol} / \mathrm{L})$ should be avoided; and insulin should be stopped when the blood glucose level drops $<70 \mathrm{mg} / \mathrm{dL}(<3.9 \mathrm{mmol} / \mathrm{L}$; Table 5.3 shows the titration protocol of the Indian guideline [8]). Despite absence of trials, the guideline recommended intravenous over subcutaneous insulin because of the latter's unreliable absorption and unpredictable effects and risk of delayed hypoglycemia. Finally, they recommended monitoring capillary blood glucose every hour or more frequently (e.g., every 20-30 min in case of hypoglycemia, until hypoglycemia resolves).

A few small trials have investigated oral antihyperglycemic agents for blood glucose control in ICU patients. Treatment with twice daily oral metformin was shown to be as effective as continuous intravenous administration of insulin in reducing the 
Table 5.3 Example of a simple protocol of blood glucose control, as proposed for Indian intensive care units

\begin{tabular}{|c|c|}
\hline \multicolumn{2}{|c|}{ Start intravenous insulin when blood glucose level $>180 \mathrm{mg} / \mathrm{dL}$} \\
\hline \multicolumn{2}{|c|}{$\begin{array}{l}\text { Start insulin infusion (U/L) by dividing the blood glucose value in }(\mathrm{mg} / \mathrm{dL}) \text { by } 100 \text { and } \\
\text { rounding it off to the nearest decimal (e.g., if blood glucose level is } 237 \mathrm{mg} / \mathrm{dL} \text {, then start } \\
\text { insulin infusion at a rate of } 2 \text { units/h, and, e.g., if blood glucose value is } 387 \mathrm{mg} / \mathrm{dL} \text {, then start } \\
\text { insulin infusion at a rate of } 4 \text { units } / \mathrm{h} \text { ) }\end{array}$} \\
\hline \multicolumn{2}{|c|}{ Titrate intravenous insulin dosage according to the prevailing blood glucose level: } \\
\hline$<110 \mathrm{mg} / \mathrm{dL}$ & No insulin \\
\hline $110-149 \mathrm{mg} / \mathrm{dL}$ & $1.0 \mathrm{unit} / \mathrm{h}$ \\
\hline $150-99 \mathrm{mg} / \mathrm{dL}$ & 2.0 units/h \\
\hline $200-249 \mathrm{mg} / \mathrm{dL}$ & 2.5 units $/ \mathrm{h}$ \\
\hline $250-299 \mathrm{mg} / \mathrm{dL}$ & 3.0 units/h \\
\hline $300-349 \mathrm{mg} / \mathrm{dL}$ & 3.5 units/h \\
\hline $350-399 \mathrm{mg} / \mathrm{dL}$ & 4.0 units/h \\
\hline $400-449 \mathrm{mg} / \mathrm{dL}$ & 4.5 units/h \\
\hline $450-499 \mathrm{mg} / \mathrm{dL}$ & 5.0 units $/ \mathrm{h}$ \\
\hline $500-549 \mathrm{mg} / \mathrm{dL}$ & 5.5 units $/ \mathrm{h}$ \\
\hline $550-599 \mathrm{mg} / \mathrm{dL}$ & 6.0 units/h \\
\hline
\end{tabular}

Adapted from [8]. To convert $\mathrm{mg} / \mathrm{dL}$ to $\mathrm{mmol} / \mathrm{L}$, divide by 18

blood glucose level in a trial in 51 critically ill trauma patients who presented with hyperglycemia [185]. Of note, it remained unclear what blood glucose targets were used in patients treated with insulin, and blood glucose levels were only marginally reduced over the 3-day observation period. Also, it was not mentioned how frequent blood glucose levels were measured, and incidence of hypoglycemia was not reported. In a trial of 24 critically ill patients after major trauma or non-abdominal surgeries, continuous intravenous administration of insulin caused a greater reduction in blood glucose concentration than metformin alone, but the latter strategy required less attention and trained personnel [186]. Hypoglycemia did not occur in this trial. A third trial in 21 ICU patients with systemic inflammatory response syndrome compared oral metformin plus intravenous insulin to intravenous insulin and found reduced insulin requirement and nursing workload with similar glucose control [187]. All trials were at high risk of bias-they lacked a description of randomization and allocation concealment-one trial was described as double-blinded but with no description of procedures [186], and all trials excluded some patients after randomization.

We did not locate trials of subcutaneous vs. intravenous insulin in critically ill patients, but pharmacologic considerations suggest that titration of insulin dose in response to changing plasma glucose values is much more feasible with intravenous administration.

Critical illness-associated hyperglycemia is common, and short-acting insulin is widely available, cheap, and on the WHO Essential Medicines List [89]. Blood glucose control with continuous intravenous insulin is a complex intervention that requires a continuous infusion pump and close monitoring, with an increased risk for hypoglycemia when blood glucose monitoring is insufficient. Choosing a higher 
glucose threshold and using a simple insulin titration protocol applicable for all ICU patients could reduce complexity and costs. Frequent blood glucose measurements, as suggested in the Indian guideline for blood glucose control [8], may only be feasible and affordable when using finger-stick blood glucose tests, but these remain less accurate than more costly venous or arterial blood samples.

Use of the cheap and widely available metformin may simplify blood glucose control in critically ill patients. However, concerns remain over the risk of lactic acidosis [189], uncertain biological availability of orally administered antihyperglycemic agents, and lack of adequate trial data. The US Food and Drug Administration label for metformin advises that metformin is contraindicated in patients with an estimated glomerular filtration rate (eGFR) $<30 \mathrm{~mL} / \mathrm{min} / \mathrm{m}^{2}$, not recommended when eGFR is $30-45 \mathrm{~mL} / \mathrm{min} / \mathrm{m}^{2}$, and should be withheld "in the presence of any condition associated with hypoxemia, dehydration, or sepsis."

After reviewing the evidence (no additional trials from low-resource ICUs) and considering availability, feasibility, affordability, and safety, our recommendations are consistent with the Surviving Sepsis guidelines and the Indian guidelines [8]. We make no recommendations regarding metformin or other oral antidiabetic agents for blood glucose control in the absence of adequate evidence from trials. We recommend a protocolized approach to blood glucose management in ICU patients with sepsis, commencing when blood glucose $>180 \mathrm{mg} / \mathrm{dL}(>10 \mathrm{mmol} / \mathrm{L})$, with a target blood glucose value $\leq 180 \mathrm{mg} / \mathrm{dL}$ ( $\leq 10 \mathrm{mmol} / \mathrm{L}$ ) (high quality of evidence). The group believes that blood glucose levels obtained with finger-stick blood glucose tests be interpreted with caution, as these measurements may not accurately estimate arterial blood or plasma glucose values (ungraded good practice statement). The group believes that a simple protocol for blood glucose management should be implemented for all critically ill patients but only if frequent blood glucose monitoring is feasible, safe, and affordable (ungraded good practice statement). The group believes that insulin should be administered intravenously rather than subcutaneously in ICU patients with sepsis (ungraded good practice statement).

\subsection{Enteral Feeding in Patients with Sepsis in Resource-Limited ICUs}

Nutrition is an integral component of critical care and evidence relating to its efficacy, timing, composition, and route of administration has evolved substantially over the past two decades. Although nutrition is no longer considered a purely supportive element administered to critically ill patients in order to maintain lean body mass, malnutrition and undernutrition remain a commonly encountered entity in patients worldwide. Malnutrition is often unrecognized and is an independent risk factor for increased morbidity, increased length of hospital stay and hospital costs, delayed recovery, readmission, impaired quality of life, and mortality [190]. This entity is of major relevance in resource-limited settings. 
Appropriately administered enteral nutrition (EN) is now believed to be associated with a reduction in complications, duration of stay in the ICU, and improved patient outcomes [191, 192]. The provision of enteral nutrition plays a pivotal role in maintaining gut integrity, thereby limiting the potential translocation of microorganisms into the bloodstream, and is thought to favorably modulate stress and the systemic inflammatory response, with subsequent diminution of cellular injury and attenuation of disease severity [191-194]. Additional benefits of enteral nutrition include its role in stress ulcer prophylaxis [2, 68, 191-193] and facilitation of electrolyte replacement.

A MEDLINE and publication search did not produce any trials that directly answered the question posed. The search identified two papers on recommendations for sepsis management in resource-limited settings [2, 68] and a sepsis guideline from Pakistan [69]. Several additional studies and guidelines from resource-rich ICUs were identified and are discussed below.

Published guidelines are not consistent on recommendations for the timing and amount of enteral feeding. The 2016 Surviving Sepsis guidelines suggest early initiation of enteral feeding rather than a complete fast or only IV glucose in critically ill patients with sepsis or septic shock who can be fed enterally (low quality of evidence) and suggest either trophic/hypocaloric or early full enteral feeding in sepsis and septic shock, with advancement of feeds according to tolerance if the former strategy is used (moderate quality of evidence) [1]. The 2015 Canadian Clinical Practice Guidelines (available at www.criticalcarenutrition.com) recommend consideration of intentional underfeeding of calories (not protein) in patients with low nutrition risk, but not high nutrition risk, and recommend against initial trophic feeding in ARDS. The 2016 SCCM/ASPEN guidelines recommend either trophic or full nutrition by EN in patients with ARDS or an expected duration of ventilation of $\geq 72 \mathrm{~h} \mathrm{[192].}$

No trial has specifically addressed early enteral feeding in septic patients. Data from a heterogeneous group of critically ill patients has revealed evidence of benefit of early enteral ( $\leq 48 \mathrm{~h})$ nutrition in reducing infectious complications [191, 193, 195-200], length of mechanical ventilation [198, 201], and length of ICU and hospital stays [198, 201], with a trend toward decreased mortality [192].

Several guidelines, recommendations, and opinion papers warn against the use of early enteral nutrition in hemodynamically unstable patients because of the risk of gastrointestinal ischemia [191, 202]. Suggestions regarding the initiation of enteral nutrition for resource-limited environments advocate administration as early as possible but only after the patient has been adequately resuscitated and is fully awake, or if intubated, after hemodynamic function has stabilized [2, 68]. Additionally, patients receiving EN should be assessed for the risk of aspiration, and steps to reduce this risk should be employed. One small trial in Bangladesh of early nasogastric EN in non-intubated patients with malaria and depressed level of consciousness was terminated early because of an increased aspiration risk in the early feeding group [203].

Risk factors for aspiration are described (Table 5.4) [192]. The potential association of bolus EN with aspiration has been shown [204], and recent guidelines 
Table 5.4 Risk factors for aspiration

\begin{tabular}{l|l}
\hline Inability to protect the airway & Neurologic deficits \\
\hline Reduced/diminished level of consciousness & Age $>70$ years \\
\hline Supine position & Inadequate nurse/patient ratio \\
\hline Presence of nasoenteric enteral access device & Gastroesophageal reflux \\
\hline Mechanical ventilation & Transportation out of ICU \\
\hline Poor oral care & Use of bolus intermittent EN \\
\hline
\end{tabular}

Adapted from [192]

suggest continuous EN for high-risk patients or those intolerant of bolus gastric EN [192]. Additional benefits of continuous EN may include fewer interruptions in delivery and delivery of an overall greater volume [205-210]. Additional measures to limit the risk of aspiration include the use of promotility agents, elevation of the head of the bed to $30-45^{\circ}$, chlorhexidine oral care, reduction in the levels of sedation and analgesia, and limiting transportation out of the ICU for diagnostic tests and procedures [211]. Measurement of gastric residual volumes has not been shown to reduce aspiration risk. Most recent guidelines, commentaries, and reviews recommend that gastric residuals not be used to monitor ICU patients on EN [202, 212]. Promotility agents, including metoclopramide $(10 \mathrm{mg}$ three to four times daily) and erythromycin (3-7 mg/kg per day), have been advocated in resource-rich environments in patients at high risk of aspiration. Adverse effects include dyskinesia in the elderly with metoclopramide and cardiac toxicity and concerns regarding bacterial resistance with erythromycin [192, 202, 213]. This practice may not always be feasible in resource-limited environments. Elevation of the head of the bed to $30-45^{\circ}[214,215]$ and chlorhexidine oral care $[216,217]$ have been shown to significantly reduce the incidence of pneumonia.

Energy and protein requirements and methods to calculate them in critically ill patients have been the subject of much debate. Weight-based formulations are regarded as acceptable estimates of nutritional requirements in most critically ill patients (criticalcarenutrition.com), based on lack of evidence for indirect calorimetry [218-221].

Nutrition encompasses the provision of macronutrients (protein, lipid, carbohydrate) and micronutrients (vitamins and minerals/trace elements) (Table 5.5). Energy requirements for the critically ill are generally in the range of $25-30 \mathrm{kcal} /$ $\mathrm{kg} /$ day, with protein requirements $1.2-2.0 \mathrm{~g} / \mathrm{kg} / \mathrm{day}$, with $1.5 \mathrm{~g} / \mathrm{kg} /$ day generally regarded as being appropriate [192, 199, 202, 220, 222]. This calculation is not necessarily applicable in obese patients where high-protein, hypocaloric feeding has more recently been advocated (2.0-2.5 g protein/kg ideal body weight/day and $65-70 \%$ of caloric requirements) to maintain lean body mass, promote loss of fat mass, and improve clinical outcome [192, 202, 223-225]. Vitamins and trace elements are organic compounds and ions that usually act as cofactors for enzymes involved in metabolic pathways or are structurally integral components of enzymes 
Table 5.5 Suggested average daily nutritional requirements for most critically ill patients

\begin{tabular}{l|l}
\hline $\begin{array}{l}\text { Energy requirements } \\
\text { Macronutrients }\end{array}$ & $25 \mathrm{kcal} / \mathrm{kg}$ \\
\hline Protein & $1.5 \mathrm{~g} / \mathrm{kg}(1 \mathrm{~g}$ protein $=4 \mathrm{kcal})$ \\
\hline Carbohydrate & $\begin{array}{l}4 \mathrm{~g} / \mathrm{kg}(1 \mathrm{~g} \\
\text { carbohydrate }=3.75 \mathrm{kcal})\end{array}$ \\
\hline Lipid & $1 \mathrm{~g} / \mathrm{kg}(1 \mathrm{~g} \mathrm{lipid} / \mathrm{fat}=9.3 \mathrm{kcal})$ \\
\hline Electrolytes & $1-2 \mathrm{mmol} / \mathrm{kg}$ \\
\hline Sodium & $1 \mathrm{mmol} / \mathrm{kg}$ \\
\hline Potassium & $1-2 \mathrm{mmol} / \mathrm{kg}$ \\
\hline Chloride & $0.1 \mathrm{mmol} / \mathrm{kg}$ \\
\hline Calcium & $0.1 \mathrm{mmol} / \mathrm{kg}$ \\
\hline Magnesium & $0.1-0.4 \mathrm{mmol} / \mathrm{kg}$ \\
\hline Phosphate & \\
\hline Vitamins & \\
\hline Water-soluble-B complex, folate, vitamin C, vitamin $\mathrm{B}_{12}$ & \\
\hline Fat-soluble-A, D, E, K & \\
\hline Trace elements & $10 \mathrm{mg}$ \\
\hline Iron & $15 \mathrm{mg}$ \\
\hline Zinc & $3 \mathrm{mg}$ \\
\hline Copper & $150 \mu \mathrm{g}$ \\
\hline Iodine & $5 \mu \mathrm{g}$ \\
\hline Manganese & $200 \mu \mathrm{g}$ \\
\hline Chromium & $200 \mu \mathrm{g}$ \\
\hline Selenium &
\end{tabular}

Adapted from [192, 199, 202, 218, 235]

that may be involved in electron transfer. The provision of antioxidant vitamins and trace elements has been associated with improved outcome in several trials [192, 226-229], but the signal has not been uniform, and a recent systematic review found no benefit of selenium [230].

Recommendations for resource-limited environments have suggested that EN be administered as early as possible but only after the patient has been fully resuscitated, demonstrates the ability to swallow, and is awake, in which case small amounts of food and drink may be allowed [2, 69]. The Sepsis Guidelines for Pakistan recommend that in basic hospitals (without intensive care backup and with general physicians), oral feeding as tolerated should be commenced within $48 \mathrm{~h}$ instead of only intravenous glucose. They suggest that in intermediate setups (hospitals with level 2 ICUs that are managed by non-intensivists and with access to in-house basic laboratory and diagnostic facilities), enteral feeding be considered within $48 \mathrm{~h}$ of sepsis, starting with $500 \mathrm{kcal} /$ day and gradually advanced as tolerated. These guidelines advise against full caloric feed in the first week. In tertiary care setups, initiation of EN is recommended within $48 \mathrm{~h}$, with parenteral nutrition (PN) alone or to supplement enteral feeding not recommended for the first 7 days of a severe infection [69]. 
Type of enteral feed and the selection of an appropriate enteral formulation have been the subjects of many investigations. In resource-limited environments where commercial feeds may not be available or affordable, hospital-prepared foods may be administered to the patient. Recipes may vary according to countries, regions, and available ingredients. Recommendations include the administration of milk supplemented by cooking oil, salt, sugar, soya, and a multivitamin tablet via a nasogastric tube in intubated hemodynamically stable patients [2] to mixtures involving eggs, milk powder, soya, maize oil, rice, squash, flour, sugar, and fruit. Mixing these foodstuffs in a blender with subsequent administration has been suggested (Towey R, Dunser M, Mer M-personal communications) but may result in unpredictable levels of both macro- and micronutrients. Where commercially available feeds are available, a standard polymeric formula is recommended [192]. These preparations contain intact proteins, fats, and carbohydrates (which require digestion prior to absorption), in addition to electrolytes, trace elements, vitamins, and fibers, and tend to be lactose-free. Commonly used ingredients in these products include the casein (protein from milk), soy protein, maize and soya oils, and the carbohydrate maltodextrin. In general, a ready-to-use standard feed will contain $1 \mathrm{kcal}$ and $0.04 \mathrm{~g}$ protein per $\mathrm{mL}$ and is usually well tolerated [192].

The utilization and employment of feeding protocols are advocated in several guidelines, studies, commentaries, and recommendations. They are associated with an increase in the overall percentage of nutrition provided and may also positively impact outcome [68, 192, 202, 231-234].

Complications of nutritional support include the refeeding syndrome in patients who are severely malnourished or who have undergone a significant period of starvation. The mechanism relates to in a loss of intracellular electrolytes in starvation or undernutrition, followed by an insulin-mediated influx of electrolytes and thiamine into the cells when carbohydrate is provided, which can result in rapid and marked reductions in serum levels of phosphate, magnesium, potassium, and calcium. Patients may also develop lactic acidosis. Clinical features include edema, diarrhea, neuromuscular abnormalities, seizures, coma, cardiac arrhythmias, and respiratory failure. Risk factors for the refeeding syndrome include a BMI of less than $18.5 \mathrm{~kg} / \mathrm{m}^{2}$; weight loss of greater than $10-15 \%$ in the prior 3-6 months; little or no nutritional intake for more than 5 days; history of alcohol abuse or drugs including insulin, chemotherapy, antacids, or diuretics; and very low levels of phosphate, potassium, and magnesium. At-risk patients should be identified, and feeding must be commenced slowly. It has been suggested that feeding commence at 5-10 kcal/kg/day with a gradual escalation over 4-7 days. Electrolytes must be closely monitored and replaced. Thiamine and other B vitamins should be given intravenously prior to commencing feeding and then daily for at least 3 days [235].

Overfeeding should be avoided as it may be associated with fluid overload, worsening renal function, hyperglycemia, hyperlipidemia, fatty liver, and hypercapnia (particularly with excess carbohydrate administration) with delayed weaning from mechanical ventilation more difficult. It has also been associated with a less favorable outcome [202, 235]. 
Enteral feeding is feasible, readily available, and can be made affordable. Parenteral nutrition is generally not available. Patients should be adequately resuscitated, hemodynamically stable, and caution exercised to limit the possibility of aspiration. Where commercial feeds are not available, hospital-prepared foods may be administered. Non-intubated patients, in whom oral feeding is to be initiated, should be awake and able to swallow. Steps in the care of the patient fed enterally with a gastric tube may be remembered using our coined acronym "COPE" and include continuous infusion, oral care with chlorhexidine, prokinetic agent use (as needed and where feasible), and elevation of the head of the bed $\left(30-45^{\circ}\right)$.

After reviewing the evidence (no additional trials from low-resource ICUs) and considering availability, feasibility, affordability, and safety, our recommendations are consistent with the Surviving Sepsis guidelines, except when noted. We make no recommendations regarding PN due to general lack of availability and therefore relevance to resource-limited ICUs. We suggest early enteral feeding as tolerated in patients with sepsis and septic shock (low quality of evidence). Additional considerations include starting oral or enteral intake within $24-48 \mathrm{~h}$ in adequately resuscitated and hemodynamically stable patients, taking measures to reduce the risk of aspiration, and being aware of the refeeding syndrome in the first few days following EN initiation in severely malnourished or starved patients. The risk of aspiration may be increased in enterally fed non-intubated comatose patients with inadequate nursing supervision. We suggest either early trophic/hypocaloric or early full enteral feeding in critically ill patients with sepsis or septic shock; if trophic/hypocaloric feeding is the initial strategy, then feeds should be advanced according to patient tolerance (moderate quality of evidence). We suggest advancing feeds over the first week of ICU stay and note that many patients in low-resource ICUs would be expected to be at high nutrition risk and therefore to benefit from full enteral feeding. We suggest establishing the energy and protein requirements to determine the goals of nutrition therapy using weight-based equations (low quality of evidence). This recommendation is consistent with the 2015 Canadian Clinical Practice Guidelines (available at www.criticalcarenutrition.com), which makes no recommendation on indirect calorimetry vs. predictive equations. We suggest a feeding protocol to optimize delivery EN (moderate quality of evidence). This recommendation is consistent with the 2015 Canadian Clinical Practice Guidelines (available at www.criticalcarenutrition.com).

\subsection{Dialysis in Patients with Sepsis-Induced Acute Kidney Damage in Resource-Limited ICUs}

Although population-based data on the burden of acute kidney injury (AKI) are sparse, acute and chronic renal failure have been estimated to account for approximately $3 \%$ of all deaths in India [236], and AKI likely contributes to a much higher proportion of deaths from sepsis. In low-resource rural settings, communityacquired AKI is more common than hospital-acquired AKI in medically complex 
patients and typically affects young previously healthy patients who develop this complication after obstetrical crisis, trauma, poisoning, or sepsis. Many patients with these conditions present late to hospital with established AKI that does not improve with resuscitation [237], raising the importance of renal replacement therapy for these conditions as a bridge to recovery. Logistical barriers to the deployment of IHD in these settings include lack of reliable electricity and water supply. In contrast, gravity-based PD can be implemented and in theory is more sustainable because of the requirement for consumables only.

No recent trials of IHD vs. PD in sepsis were identified in a search of recent MEDLINE references (2012-2016). One trial compared high-volume peritoneal dialysis to extended daily dialysis in ICUs in two Brazilian hospitals [238]; nearly half the enrolled patients had sepsis. Results of the intention-to-treat analysis were not reported, and treatment groups did not appear well-matched at baseline; overall mortality was $64 \%$ and did not differ between groups. The search also revealed several observational studies of adults [239-245] or children [242, 245-248] treated with PD or HD, including one study of CRRT under combat conditions [249]. Among these studies, the median mortality was $30 \%$. Several commentaries have described the Saving Young Lives program of the International Society of Nephrology [250-252], designed to establish sustainable acute PD programs in very low-resource settings. Preliminary data describe 175 patients treated over 33 months in 8 hospitals in Africa and Asia, with one-third of patients surviving to discharge with normal renal function [253].

Surviving Sepsis guidelines make no recommendations about the modality of renal replacement in septic patients [1]. A prominent early trial from a single center in Vietnam showed that continuous hemofiltration vs. peritoneal dialysis reduced mortality in patients with severe acute kidney injury due to infection (malaria or sepsis) [254]. More recently, a systematic review and meta-analysis [255] included seven cohort studies and four trials of IHD vs. PD; the trials were conducted in middle-income countries (Nigeria, India, Brazil, and Vietnam), and the observational studies were conducted in high- or middle-income countries. The risk of bias of the trials was not described in detail, although all scored 3 or below on the 5-point Jadad scale, and therefore could be considered as low quality. The quality of the observational studies was not assessed. Meta-analyses showed no difference in mortality (OR in trials $1.50,95 \% \mathrm{CI} 0.46-4.86$; OR in observational studies $0.96,95 \% \mathrm{CI}$ $0.53-1.71)$.

Recent literature has emphasized the high potential for feasible and cost-effective widespread deployment of PD to very low-resource settings, notwithstanding challenges of patient selection, ongoing training, and program sustainability [253].

Our recommendation is not informed by the Surviving Sepsis guidelines. We suggest that patients with sepsis-induced AKI requiring renal replacement therapy be supported with PD in centers with no current access to renal replacement therapy (very low quality of evidence; case series only).

Remark: In centers with functioning IHD programs, we suggest that this modality continue to be used. 


\subsection{Fluid Strategies in Patients with Sepsis in Resource- Limited ICUs}

Sepsis is traditionally treated with large volume fluid resuscitation, which frequently causes accumulation of bodily fluids. However, numerous studies have demonstrated that a positive fluid balance is independently associated with organ dysfunction and decreased survival [256-261]. Achieving a negative fluid balance, or "de-resuscitation," could improve organ function and outcome of critically ill patients [262, 263].

The MEDLINE search did not find trials of "de-resuscitation" from resourcelimited ICUs. The search, however, identified one recent systematic review including trials and observational studies that collectively enrolled a broad population of patients and compared "conservative" to "nonconservative" fluid strategies [264]. We also discuss one trial of fluid strategies in patients with ARDS [263].

The 2016 Surviving Sepsis guidelines contain recommendations pertaining to initial resuscitation, but do not address fluid management beyond that phase [1].

The best evidence that "de-resuscitation" may improve outcomes of critically ill patients comes from a randomized controlled trial in 1000 patients with ARDS [263]. In this trial, a "conservative" and a "liberal" strategy of fluid management using complex but explicit protocols were compared in patients not in shock. In this factorial trial, patients were also randomized to pulmonary artery vs. central venous catheterization. The mean cumulative fluid balance during the first 7 days was significantly more positive in the "liberal" strategy group $(6992 \pm 502 \mathrm{~mL}$ versus $-136 \pm 491 \mathrm{~mL}$ ). While the difference in mortality at 60 days ( $25.5 \mathrm{vs.} 28.4 \%)$ was not statistically significant, the "conservative" strategy improved oxygenation and lung function and increased the number of ventilator-free days (14.6 \pm 0.5 vs. $12.1 \pm 0.5$ days) as well as the number of ICU-free days ( $13.4 \pm 0.4$ vs. $11.2 \pm 0.4$ days) during the first 28 days. Notably, while the "conservative" strategy did not increase the incidence of shock during the study or the use of dialysis, it did result in higher levels of blood urea nitrogen, bicarbonate, hemoglobin, and albumin. Also, there were no significant differences in the number of failure-free days for other organs other than the lung. Of note, although most patients in this trial met the criteria for sepsis, it is unclear whether a "restrictive" strategy will have similar beneficial effects when given to septic patients (i.e., in the absence of ARDS).

Trials comparing "conservative" with "liberal" strategy of fluid management in patients with sepsis are lacking. One recently published systematic review [264], including observational studies or trials (often testing interventions other than fluid strategies), showed that the cumulative fluid balance after 1 week of ICU stay was 4.4 L more positive in non-survivors compared to survivors. A "conservative" fluid strategy resulted in a less positive cumulative fluid balance of $5.6 \mathrm{~L}$ after 1 week of ICU stay, which was associated with a lower mortality compared to patients treated with a more liberal fluid management strategy (odds ratio, 0.42 [0.32-0.55]). It should be noted, however, that this systematic review included studies of a broad population of patients (including elective surgical patients) and did not report the 
most unbiased analysis possible, i.e., of outcomes in trials of patients randomized to conservative vs. liberal fluid strategies.

It should be noted that the explicit protocols for fluid management in the trial in ARDS patients [263] were quite complex. At least every $4 \mathrm{~h}$, patients were assigned to 1 of as many as 20 protocol cells on the basis of 4 variables: central venous pressure or pulmonary artery occlusion pressure, the presence or absence of shock (a mean systemic arterial pressure $<60 \mathrm{mmHg}$ or the need for a vasopressor), the presence or absence of oliguria (less than $0.5 \mathrm{~mL} / \mathrm{kg} / \mathrm{h}$ ), and the presence or absence of ineffective circulation (cardiac index of less than $2.5 \mathrm{~L} / \mathrm{min} / \mathrm{m}^{2}$ or cold, mottled skin with a capillary refilling time of more than $2 \mathrm{~s}$ ), with each cell being associated with an intervention and a reassessment interval. Apart from this complex approach, the 4-hourly reassessment and the need for a central venous catheter or pulmonary artery catheter could hamper feasibility and affordability in resource-limited ICUs.

Our recommendations are not informed by the Surviving Sepsis guidelines. We suggest conservative fluid administration in patients with sepsis who are not in shock (low quality of evidence; indirect evidence from trials in other forms of critical illness). Conservative fluid administration requires development of a protocol (e.g., incorporating shock, oliguria, jugular venous pressure, capillary refill; see reference [265] for a sample resuscitation protocol incorporating some clinical signs). The protocol should specify the timing of re-evaluation between fluid interventions determined by patient stability. No de-resuscitation protocol has been tested in lowresource ICUs. The role of pressure monitoring via a central venous catheter to direct resuscitation and de-resuscitation is contentious [266, 267]. Conservative fluid administration may be associated with higher levels of blood urea nitrogen, bicarbonate, hemoglobin, and albumin.

\section{References}

1. Rhodes A, Evans LE, Alhazzani W, Levy MM, Antonelli M, Ferrer R, Kumar A, Sevransky JE, Sprung CL, Nunnally ME, Rochwerg B, Rubenfeld GD, Angus DC, Annane D, Beale RJ, Bellinghan GJ, Bernard GR, Chiche JD, Coopersmith C, De Backer DP, French CJ, Fujishima S, Gerlach H, Hidalgo JL, Hollenberg SM, Jones AE, Karnad DR, Kleinpell RM, Koh Y, Lisboa TC, Machado FR, Marini JJ, Marshall JC, Mazuski JE, McIntyre LA, McLean AS, Mehta S, Moreno RP, Myburgh J, Navalesi P, Nishida O, Osborn TM, Perner A, Plunkett CM, Ranieri M, Schorr CA, Seckel MA, Seymour CW, Shieh L, Shukri KA, Simpson SQ, Singer M, Thompson BT, Townsend SR, Van der Poll T, Vincent JL, Wiersinga WJ, Zimmerman JL, Dellinger RP (2017) Surviving Sepsis Campaign: international guidelines for management of sepsis and septic shock: 2016. Intensive Care Med 43(3):304-377.

2. Dunser MW, Festic E, Dondorp A, Kissoon N, Ganbat T, Kwizera A, Haniffa R, Baker T, Schultz MJ, Global Intensive Care Working Group of European Society of Intensive Care Medicine. Recommendations for sepsis management in resource-limited settings. Intensive Care Med. 2012;38:557-74.

3. Schünemann H, Brożek J, Guyatt G, Oxman A, editors. GRADE handbook for grading quality of evidence and strength of recommendations. Updated October 2013 [guidelinedevelopment. org/handbook]. The GRADE Working Group. 2013.

4. Serpa Neto A, Schultz MJ, Festic E. Ventilatory support of patients with sepsis or septic shock in resource-limited settings. Intensive Care Med. 2016;42:100-3. 
5. Guyatt GH, Alonso-Coello P, Schunemann HJ, Djulbegovic B, Nothacker M, Lange S, Murad $\mathrm{MH}, \mathrm{Akl}$ EA. Guideline panels should seldom make good practice statements: guidance from the GRADE Working Group. J Clin Epidemiol. 2016;80:3-7.

6. Murray MJ, DeBlock H, Erstad B, Gray A, Jacobi J, Jordan C, McGee W, McManus C, Meade M, Nix S, Patterson A, Sands MK, Pino R, Tescher A, Arbour R, Rochwerg B, Murray CF, Mehta S. Clinical practice guidelines for sustained neuromuscular blockade in the adult critically Ill patient. Crit Care Med. 2016;44:2079-103.

7. Jacobson BF, Louw S, Buller H, Mer M, de Jong PR, Rowji P, Schapkaitz E, Adler D, Beeton A, Hsu HC, Wessels P, Haas S, South African Society of Thrombosis and Haemostasis. Venous thromboembolism: prophylactic and therapeutic practice guideline. S Afr Med J. 2013;103:261-7.

8. Mukherjee JJ, Chatterjee PS, Saikia M, Muruganathan A, Das AK, Diabetes Consensus Group. Consensus recommendations for the management of hyperglycaemia in critically ill patients in the Indian setting. J Assoc Physicians India. 2014;62:16-25.

9. Clinical practice guideline for nutrition support in the mechanically ventilated, critically ill adult patient. http://www.criticalcarenutrition.com/. Clinical Evaluation Research Unit, Kingston General Hospital/Queen's University. 2015.

10. Angus DC, van der Poll T. Severe sepsis and septic shock. N Engl J Med. 2013;369:840-51.

11. Fleischmann C, Scherag A, Adhikari NK, Hartog CS, Tsaganos T, Schlattmann P, Angus DC, Reinhart K. International Forum of Acute Care TrialistsAssessment of global incidence and mortality of hospital-treated sepsis. Current estimates and limitations. Am J Respir Crit Care Med. 2016;193:259-72.

12. Sweeney DA, Danner RL, Eichacker PQ, Natanson C. Once is not enough: clinical trials in sepsis. Intensive Care Med. 2008;34:1955-60.

13. Asfar P, Meziani F, Hamel JF, Grelon F, Megarbane B, Anguel N, Mira JP, Dequin PF, Gergaud S, Weiss N, Legay F, Le Tulzo Y, Conrad M, Robert R, Gonzalez F, Guitton C, Tamion F, Tonnelier JM, Guezennec P, Van Der Linden T, Vieillard-Baron A, Mariotte E, Pradel G, Lesieur O, Ricard JD, Herve F, du Cheyron D, Guerin C, Mercat A, Teboul JL, Radermacher P, SEPSIS-PAM Investigators. High versus low blood-pressure target in patients with septic shock. N Engl J Med. 2014;370:1583-93.

14. Angus DC, Barnato AE, Bell D, Bellomo R, Chong CR, Coats TJ, Davies A, Delaney A, Harrison DA, Holdgate A, Howe B, Huang DT, Iwashyna T, Kellum JA, Peake SL, Pike F, Reade MC, Rowan KM, Singer M, Webb SA, Weissfeld LA, Yealy DM, Young JD. A systematic review and meta-analysis of early goal-directed therapy for septic shock: the ARISE, ProCESS and ProMISe Investigators. Intensive Care Med. 2015;41:1549-60.

15. Caironi P, Tognoni G, Masson S, Fumagalli R, Pesenti A, Romero M, Fanizza C, Caspani L, Faenza S, Grasselli G, Iapichino G, Antonelli M, Parrini V, Fiore G, Latini R, Gattinoni L, ALBIOS Study Investigators. Albumin replacement in patients with severe sepsis or septic shock. N Engl J Med. 2014;370:1412-21.

16. Annane D, Bellissant E, Cavaillon JM. Septic shock. Lancet. 2005;365:63-78.

17. Marik PE, Pastores SM, Annane D, Meduri GU, Sprung CL, Arlt W, Keh D, Briegel J, Beishuizen A, Dimopoulou I, Tsagarakis S, Singer M, Chrousos GP, Zaloga G, Bokhari F, Vogeser M, American College of Critical Care Medicine. Recommendations for the diagnosis and management of corticosteroid insufficiency in critically ill adult patients: consensus statements from an international task force by the American College of Critical Care Medicine. Crit Care Med. 2008;36:1937-49.

18. Marik PE. Critical illness-related corticosteroid insufficiency. Chest. 2009;135:181-93.

19. Annane D. Corticosteroids for severe sepsis: an evidence-based guide for physicians. Ann Intensive Care. 2011;1:7.

20. Cohen R. Use of corticosteroids in septic shock. Minerva Anestesiol. 2011;77:190-5.

21. Marik PE, Annane D. Reduced cortisol metabolism during critical illness. N Engl J Med. 2013;369:480-1.

22. Boonen E, Van den Berghe G. Cortisol metabolism in critical illness: implications for clinical care. Curr Opin Endocrinol Diabetes Obes. 2014;21:185-92. 
23. Peeters B, Boonen E, Langouche L, Van den Berghe G. The HPA axis response to critical illness: new study results with diagnostic and therapeutic implications. Mol Cell Endocrinol. 2015;408:235-40.

24. Venkatesh B, Cohen J, Cooper M. Ten false beliefs about cortisol in critically ill patients. Intensive Care Med. 2015;41:1817-9.

25. Kertai MD, Fontes ML. Predicting adrenal insufficiency in severe sepsis: the role of plasmafree cortisol. Crit Care Med. 2015;43:715-6.

26. Cooper MS, Stewart PM. Corticosteroid insufficiency in acutely ill patients. N Engl J Med. 2003;348:727-34.

27. Patel GP, Balk RA. Systemic steroids in severe sepsis and septic shock. Am J Respir Crit Care Med. 2012;185:133-9.

28. Park HY, Suh GY, Song JU, Yoo H, Jo IJ, Shin TG, Lim SY, Woo S, Jeon K. Early initiation of low-dose corticosteroid therapy in the management of septic shock: a retrospective observational study. Crit Care. 2012;16:R3.

29. Annane D, Bellissant E, Bollaert PE, Briegel J, Keh D, Kupfer Y. Corticosteroids for treating sepsis. Cochrane Database Syst Rev. 2015:CD002243.

30. van Leeuwen HJ, van der Bruggen T, van Asbeck BS, Boereboom FT. Effect of corticosteroids on nuclear factor-kappaB activation and hemodynamics in late septic shock. Crit Care Med. 2001;29:1074-7.

31. Prigent H, Maxime V, Annane D. Science review: mechanisms of impaired adrenal function in sepsis and molecular actions of glucocorticoids. Crit Care. 2004;8:243-52.

32. Meduri GU, Muthiah MP, Carratu P, Eltorky M, Chrousos GP. Nuclear factor-kappaB- and glucocorticoid receptor alpha- mediated mechanisms in the regulation of systemic and pulmonary inflammation during sepsis and acute respiratory distress syndrome. Evidence for inflammation-induced target tissue resistance to glucocorticoids. Neuroimmunomodulation. 2005; $12: 321-38$.

33. Mesotten D, Vanhorebeek I, Van den Berghe G. The altered adrenal axis and treatment with glucocorticoids during critical illness. Nat Clin Pract Endocrinol Metab. 2008;4:496-505.

34. Annane D, Bellissant E, Sebille V, Lesieur O, Mathieu B, Raphael JC, Gajdos P. Impaired pressor sensitivity to noradrenaline in septic shock patients with and without impaired adrenal function reserve. Br J Clin Pharmacol. 1998;46:589-97.

35. Galon J, Franchimont D, Hiroi N, Frey G, Boettner A, Ehrhart-Bornstein M, O'Shea JJ, Chrousos GP, Bornstein SR. Gene profiling reveals unknown enhancing and suppressive actions of glucocorticoids on immune cells. FASEB J. 2002;16:61-71.

36. Colin G, Annane D. Corticosteroids and human recombinant activated protein C for septic shock. Clin Chest Med. 2008;29:705-12. x

37. Boonen E, Vervenne H, Meersseman P, Andrew R, Mortier L, Declercq PE, Vanwijngaerden YM, Spriet I, Wouters PJ, Vander Perre S, Langouche L, Vanhorebeek I, Walker BR, Van den Berghe G. Reduced cortisol metabolism during critical illness. N Engl J Med. 2013;368:1477-88.

38. Christ-Crain M, Stolz D, Jutla S, Couppis O, Muller C, Bingisser R, Schuetz P, Tamm M, Edwards R, Muller B, Grossman AB. Free and total cortisol levels as predictors of severity and outcome in community-acquired pneumonia. Am J Respir Crit Care Med. 2007;176:913-20.

39. Salluh JI, Bozza FA, Soares M, Verdeal JC, Castro-Faria-Neto HC, Lapa ESJR, Bozza PT. Adrenal response in severe community-acquired pneumonia: impact on outcomes and disease severity. Chest. 2008;134:947-54.

40. Hamrahian AH, Oseni TS, Arafah BM. Measurements of serum free cortisol in critically ill patients. N Engl J Med. 2004;350:1629-38.

41. Gotoh S, Nishimura N, Takahashi O, Shiratsuka H, Horinouchi H, Ono H, Uchiyama N, Chohnabayashi N. Adrenal function in patients with community-acquired pneumonia. Eur Respir J. 2008;31:1268-73.

42. Briegel J, Sprung CL, Annane D, Singer M, Keh D, Moreno R, Mohnle P, Weiss Y, Avidan A, Brunkhorst FM, Fiedler F, Vogeser M, CORTICUS Study Group. Multicenter comparison of 
cortisol as measured by different methods in samples of patients with septic shock. Intensive Care Med. 2009;35:2151-6.

43. Sprung CL, Goodman S, Weiss YG. Steroid therapy of septic shock. Crit Care Nurs Clin North Am. 2011;23:171-80.

44. Marik PE. Glucocorticoids in sepsis: dissecting facts from fiction. Crit Care. 2011;15:158.

45. Funk D, Doucette S, Pisipati A, Dodek P, Marshall JC, Kumar A, Cooperative Antimicrobial Therapy of Septic Shock Database Research Group. Low-dose corticosteroid treatment in septic shock: a propensity-matching study. Crit Care Med. 2014;42:2333-41.

46. Allen KS, Kinasewitz GT. The pendulum of corticosteroids in sepsis swings again? Crit Care Med. 2014;42:2442-3.

47. Annane D. Adjunctive treatment in septic shock: what's next? Presse Med. 2016;45:e105-9.

48. Trubelja AD. Current use of steroids in critical care. SOJ Anesthesiol Pain Manag. 2014;1:1-4.

49. Lefering R, Neugebauer EA. Steroid controversy in sepsis and septic shock: a meta-analysis. Crit Care Med. 1995;23:1294-303.

50. Cronin L, Cook DJ, Carlet J, Heyland DK, King D, Lansang MA, Fisher CJ Jr. Corticosteroid treatment for sepsis: a critical appraisal and meta-analysis of the literature. Crit Care Med. 1995;23:1430-9.

51. Annane D, Sebille V, Charpentier C, Bollaert PE, Francois B, Korach JM, Capellier G, Cohen Y, Azoulay E, Troche G, Chaumet-Riffaud P, Bellissant E. Effect of treatment with low doses of hydrocortisone and fludrocortisone on mortality in patients with septic shock. JAMA. 2002;288:862-71.

52. Bollaert PE, Charpentier C, Levy B, Debouverie M, Audibert G, Larcan A. Reversal of late septic shock with supraphysiologic doses of hydrocortisone. Crit Care Med. 1998;26:645-50.

53. Briegel J, Forst H, Haller M, Schelling G, Kilger E, Kuprat G, Hemmer B, Hummel T, Lenhart A, Heyduck M, Stoll C, Peter K. Stress doses of hydrocortisone reverse hyperdynamic septic shock: a prospective, randomized, double-blind, single-center study. Crit Care Med. 1999;27:723-32.

54. Confalonieri M, Urbino R, Potena A, Piattella M, Parigi P, Puccio G, Della Porta R, Giorgio C, Blasi F, Umberger R, Meduri GU. Hydrocortisone infusion for severe community-acquired pneumonia: a preliminary randomized study. Am J Respir Crit Care Med. 2005;171:242-8.

55. Cheng AC, West TE, Limmathurotsakul D, Peacock SJ. Strategies to reduce mortality from bacterial sepsis in adults in developing countries. PLoS Med. 2008;5:e175.

56. Siemieniuk RA, Meade MO, Alonso-Coello P, Briel M, Evaniew N, Prasad M, Alexander PE, Fei Y, Vandvik PO, Loeb M, Guyatt GH. Corticosteroid therapy for patients hospitalized with community-acquired pneumonia: a systematic review and meta-analysis. Ann Intern Med. 2015;163:519-28.

57. Torres A, Sibila O, Ferrer M, Polverino E, Menendez R, Mensa J, Gabarrus A, Sellares J, Restrepo MI, Anzueto A, Niederman MS, Agusti C. Effect of corticosteroids on treatment failure among hospitalized patients with severe community-acquired pneumonia and high inflammatory response: a randomized clinical trial. JAMA. 2015;313:677-86.

58. Cavalcanti AB, Machado FR, Berwanger O. Quality improvement intervention and mortality of critically ill patients-reply. JAMA. 2016;316:879-80.

59. Thwaites GE, Nguyen DB, Nguyen HD, Hoang TQ, Do TT, Nguyen TC, Nguyen QH, Nguyen TT, Nguyen NH, Nguyen TN, Nguyen NL, Nguyen HD, Vu NT, Cao HH, Tran TH, Pham PM, Nguyen TD, Stepniewska K, White NJ, Tran TH, Farrar JJ. Dexamethasone for the treatment of tuberculous meningitis in adolescents and adults. $\mathrm{N}$ Engl $\mathrm{J}$ Med. 2004;351:1741-51.

60. Strang JI, Kakaza HH, Gibson DG, Girling DJ, Nunn AJ, Fox W. Controlled trial of prednisolone as adjuvant in treatment of tuberculous constrictive pericarditis in Transkei. Lancet. 1987;2:1418-22.

61. Strang JI, Nunn AJ, Johnson DA, Casbard A, Gibson DG, Girling DJ. Management of tuberculous constrictive pericarditis and tuberculous pericardial effusion in Transkei: results at 10 years follow-up. QJM. 2004;97:525-35. 
62. Hoffman SL, Punjabi NH, Kumala S, Moechtar MA, Pulungsih SP, Rivai AR, Rockhill RC, Woodward TE, Loedin AA. Reduction of mortality in chloramphenicol-treated severe typhoid fever by high-dose dexamethasone. N Engl J Med. 1984;310:82-8.

63. Mer M, Richards GA. Corticosteroids in life-threatening varicella pneumonia. Chest. 1998;114:426-31.

64. Bozzette SA, Sattler FR, Chiu J, Wu AW, Gluckstein D, Kemper C, Bartok A, Niosi J, Abramson I, Coffman J, et al. A controlled trial of early adjunctive treatment with corticosteroids for Pneumocystis carinii pneumonia in the acquired immunodeficiency syndrome. California Collaborative Treatment Group. N Engl J Med. 1990;323:1451-7.

65. Ewald H, Raatz H, Boscacci R, Furrer H, Bucher HC, Briel M. Adjunctive corticosteroids for Pneumocystis jiroveci pneumonia in patients with HIV infection. Cochrane Database Syst Rev. 2015:CD006150.

66. Brouwer MC, McIntyre P, Prasad K, van de Beek D. Corticosteroids for acute bacterial meningitis. Cochrane Database Syst Rev. 2015:CD004405.

67. McGee S, Hirschmann J. Use of corticosteroids in treating infectious diseases. Arch Intern Med. 2008;168:1034-46.

68. Stephens K. Management of sepsis with limited resources. Update in Anesthesia. 28:145-55.

69. Hashmi M, Khan FH, bin Sarwar Zubairi A, Sultan ST, Haider S, Aftab S, Husain J, ul Haq A, Rao ZA, Khuwaja A, Sultan SF, Rais Z, Baloch R, Salahuddin N, Khan A, Sultan F, Chima K, Ali A, Ali G. Developing local guidelines for management of sepsis in adults: Sepsis Guidelines for Pakistan (SGP). Anaesth Pain Intensive Care. 2015;19:196-208.

70. Sprung CL, Caralis PV, Marcial EH, Pierce M, Gelbard MA, Long WM, Duncan RC, Tendler MD, Karpf M. The effects of high-dose corticosteroids in patients with septic shock. A prospective, controlled study. N Engl J Med. 1984;311:1137-43.

71. Bone RC, Fisher CJ Jr, Clemmer TP, Slotman GJ, Metz CA. Early methylprednisolone treatment for septic syndrome and the adult respiratory distress syndrome. Chest. 1987;92:1032-6.

72. Annane D, Bellissant E, Bollaert PE, Briegel J, Keh D, Kupfer Y. Corticosteroids for severe sepsis and septic shock: a systematic review and meta-analysis. BMJ. 2004;329:480.

73. Dellinger RP, Carlet JM, Masur H, Gerlach H, Calandra T, Cohen J, Gea-Banacloche J, Keh D, Marshall JC, Parker MM, Ramsay G, Zimmerman JL, Vincent JL, Levy MM, Surviving Sepsis Campaign Management Guidelines Committee. Surviving Sepsis Campaign guidelines for management of severe sepsis and septic shock. Crit Care Med. 2004;32:858-73.

74. Sprung CL, Annane D, Keh D, Moreno R, Singer M, Freivogel K, Weiss YG, Benbenishty J, Kalenka A, Forst H, Laterre PF, Reinhart K, Cuthbertson BH, Payen D, Briegel J, Corticus Study Group. Hydrocortisone therapy for patients with septic shock. N Engl J Med. 2008;358:111-24.

75. Marik PE, Pastores SM, Kavanagh BP. Corticosteroids for septic shock [letter]. N Engl J Med. 2008;358:2069-70. author reply 2070-2061

76. Vincent JL. Steroids in sepsis: another swing of the pendulum in our clinical trials. Crit Care. 2008;12:141.

77. COIITSS Study Investigators, Annane D, Cariou A, Maxime V, Azoulay E, D'Honneur G, Timsit JF, Cohen Y, Wolf M, Fartoukh M, Adrie C, Santre C, Bollaert PE, Mathonet A, Amathieu R, Tabah A, Clec'h C, Mayaux J, Lejeune J, Chevret S. Corticosteroid treatment and intensive insulin therapy for septic shock in adults: a randomized controlled trial. JAMA. 2010;303:341-8.

78. Dellinger RP, Levy MM, Carlet JM, Bion J, Parker MM, Jaeschke R, Reinhart K, Angus DC, Brun-Buisson C, Beale R, Calandra T, Dhainaut JF, Gerlach H, Harvey M, Marini JJ, Marshall J, Ranieri M, Ramsay G, Sevransky J, Thompson BT, Townsend S, Vender JS, Zimmerman JL, Vincent JL, International Surviving Sepsis Campaign Guidelines Committee, American Association of Critical-Care Nurses, American College of Chest Physicians, American College of Emergency Physicians, Canadian Critical Care Society, European Society of Clinical Microbiology and Infectious Diseases, European Society of Intensive Care Medicine, European Respiratory Society, International Sepsis Forum, Japanese Association for Acute Medicine, Japanese Society of Intensive Care Medicine, 
Society of Critical Care Medicine, Society of Hospital Medicine, Surgical Infection Society, World Federation of Societies of Intensive and Critical Care Medicine. Surviving Sepsis Campaign: international guidelines for management of severe sepsis and septic shock: 2008. Crit Care Med2008;36:296-327.

79. Annane D, Bellissant E, Bollaert PE, Briegel J, Confalonieri M, De Gaudio R, Keh D, Kupfer Y, Oppert M, Meduri GU. Corticosteroids in the treatment of severe sepsis and septic shock in adults: a systematic review. JAMA. 2009;301:2362-75.

80. Sligl WI, Milner DA Jr, Sundar S, Mphatswe W, Majumdar SR. Safety and efficacy of corticosteroids for the treatment of septic shock: a systematic review and meta-analysis. Clin Infect Dis. 2009;49:93-101.

81. Vincent JL, Serrano EC, Dimoula A. Current management of sepsis in critically ill adult patients. Expert Rev Anti-Infect Ther. 2011;9:847-56.

82. Ferrer R, Artigas A, Suarez D, Palencia E, Levy MM, Arenzana A, Perez XL, Sirvent JM, Edusepsis Study Group. Effectiveness of treatments for severe sepsis: a prospective, multicenter, observational study. Am J Respir Crit Care Med. 2009;180:861-6.

83. Levy MM, Dellinger RP, Townsend SR, Linde-Zwirble WT, Marshall JC, Bion J, Schorr C, Artigas A, Ramsay G, Beale R, Parker MM, Gerlach H, Reinhart K, Silva E, Harvey M, Regan S, Angus DC. The Surviving Sepsis Campaign: results of an international guidelinebased performance improvement program targeting severe sepsis. Intensive Care Med. 2010;36:222-31.

84. Povoa P, Salluh JI, Martinez ML, Guillamat-Prats R, Gallup D, HR A-K, Thompson BT, Ranieri VM, Artigas A. Clinical impact of stress dose steroids in patients with septic shock: insights from the PROWESS-Shock trial. Crit Care. 2015;19:193.

85. Beale R, Janes JM, Brunkhorst FM, Dobb G, Levy MM, Martin GS, Ramsay G, Silva E, Sprung CL, Vallet B, Vincent JL, Costigan TM, Leishman AG, Williams MD, Reinhart K. Global utilization of low-dose corticosteroids in severe sepsis and septic shock: a report from the PROGRESS registry. Crit Care. 2010;14:R102.

86. Casserly B, Gerlach H, Phillips GS, Lemeshow S, Marshall JC, Osborn TM, Levy MM. Lowdose steroids in adult septic shock: results of the Surviving Sepsis Campaign. Intensive Care Med. 2012;38:1946-54.

87. Venkatesh B, Myburgh J, Finfer S, Webb SA, Cohen J, Bellomo R, McArthur C, Joyce CJ, Rajbhandari D, Glass P, Harward M, ANZICS CTG Investigators. The ADRENAL study protocol: adjunctive corticosteroid treatment in critically ill patients with septic shock. Crit Care Resusc. 2013;15:83-8.

88. Annane D, Buisson CB, Cariou A, Martin C, Misset B, Renault A, Lehmann B, Millul $\mathrm{V}$, Maxime V, Bellissant E, APPROCHSS Investigators for the TRIGGERSEP Network. Design and conduct of the activated protein $\mathrm{C}$ and corticosteroids for human septic shock (APROCCHSS) trial [Erratum in: Ann Intensive Care 2016 Dec; 6(1): 79]. Ann Intensive Care. 2016;6:43.

89. WHO model lists of essential medicines. 2015. World Health Organization. http://www.who. int/medicines/publications/essentialmedicines/en/.

90. Strom T, Johansen RR, Prahl JO, Toft P. Sedation and renal impairment in critically ill patients: a post hoc analysis of a randomized trial. Crit Care. 2011;15:R119.

91. Strom T, Martinussen T, Toft P. A protocol of no sedation for critically ill patients receiving mechanical ventilation: a randomised trial. Lancet. 2010;375:475-80.

92. Pandharipande PP, Pun BT, Herr DL, Maze M, Girard TD, Miller RR, Shintani AK, Thompson JL, Jackson JC, Deppen SA, Stiles RA, Dittus RS, Bernard GR, Ely EW. Effect of sedation with dexmedetomidine vs lorazepam on acute brain dysfunction in mechanically ventilated patients: the MENDS randomized controlled trial. JAMA. 2007;298:2644-53.

93. Kollef MH, Levy NT, Ahrens TS, Schaiff R, Prentice D, Sherman G. The use of continuous i.v. sedation is associated with prolongation of mechanical ventilation. Chest. 1998;114:541-8.

94. Brook AD, Ahrens TS, Schaiff R, Prentice D, Sherman G, Shannon W, Kollef MH. Effect of a nursing-implemented sedation protocol on the duration of mechanical ventilation. Crit Care Med. 1999;27:2609-15. 
95. Aitken LM, Bucknall T, Kent B, Mitchell M, Burmeister E, Keogh S. Sedation protocols to reduce duration of mechanical ventilation in the ICU: a Cochrane Systematic Review. J Adv Nurs. 2016;72:261-72.

96. Kress JP, Pohlman AS, O'Connor MF, Hall JB. Daily interruption of sedative infusions in critically ill patients undergoing mechanical ventilation. N Engl J Med. 2000;342:1471-7.

97. Schweickert WD, Gehlbach BK, Pohlman AS, Hall JB, Kress JP. Daily interruption of sedative infusions and complications of critical illness in mechanically ventilated patients. Crit Care Med. 2004;32:1272-6.

98. Kress JP, Vinayak AG, Levitt J, Schweickert WD, Gehlbach BK, Zimmerman F, Pohlman AS, Hall JB. Daily sedative interruption in mechanically ventilated patients at risk for coronary artery disease. Crit Care Med. 2007;35:365-71.

99. Burry L, Rose L, McCullagh IJ, Fergusson DA, Ferguson ND, Mehta S. Daily sedation interruption versus no daily sedation interruption for critically ill adult patients requiring invasive mechanical ventilation. Cochrane Database Syst Rev. 2014:CD009176.

100. Ma P, Liu J, Xi X, Du B, Yuan X, Lin H, Wang Y, Su J, Zeng L. Practice of sedation and the perception of discomfort during mechanical ventilation in Chinese intensive care units. J Crit Care. 2010;25:451-7.

101. Kress JP, Gehlbach B, Lacy M, Pliskin N, Pohlman AS, Hall JB. The long-term psychological effects of daily sedative interruption on critically ill patients. Am J Respir Crit Care Med. 2003;168:1457-61.

102. Treggiari MM, Romand JA, Yanez ND, Deem SA, Goldberg J, Hudson L, Heidegger CP, Weiss NS. Randomized trial of light versus deep sedation on mental health after critical illness. Crit Care Med. 2009;37:2527-34.

103. Jackson JC, Girard TD, Gordon SM, Thompson JL, Shintani AK, Thomason JW, Pun BT, Canonico AE, Dunn JG, Bernard GR, Dittus RS, Ely EW. Long-term cognitive and psychological outcomes in the awakening and breathing controlled trial. Am J Respir Crit Care Med. 2010;182:183-91.

104. Murray MJ, Cowen J, DeBlock H, Erstad B, Gray AW, Jr., Tescher AN, McGee WT, Prielipp RC, Susla G, Jacobi J, Nasraway SA, Jr., Lumb PD, Task Force of the American College of Critical Care Medicine of the Society of Critical Care Medicine, American Society of Health-System Pharmacists, American College of Chest Physicians. Clinical practice guidelines for sustained neuromuscular blockade in the adult critically ill patient. Crit Care Med. 2002;30:142-156.

105. Hansen-Flaschen JH, Brazinsky S, Basile C, Lanken PN. Use of sedating drugs and neuromuscular blocking agents in patients requiring mechanical ventilation for respiratory failure. A national survey. JAMA. 1991;266:2870-5.

106. Neto AS, Pereira VG, Esposito DC, Damasceno MC, Schultz MJ. Neuromuscular blocking agents in patients with acute respiratory distress syndrome: a summary of the current evidence from three randomized controlled trials. Ann Intensive Care. 2012;2:33.

107. Forel JM, Roch A, Marin V, Michelet P, Demory D, Blache JL, Perrin G, Gainnier M, Bongrand P, Papazian L. Neuromuscular blocking agents decrease inflammatory response in patients presenting with acute respiratory distress syndrome. Crit Care Med. 2006;34:2749-57.

108. Gainnier M, Roch A, Forel JM, Thirion X, Arnal JM, Donati S, Papazian L. Effect of neuromuscular blocking agents on gas exchange in patients presenting with acute respiratory distress syndrome. Crit Care Med. 2004;32:113-9.

109. Papazian L, Forel JM, Gacouin A, Penot-Ragon C, Perrin G, Loundou A, Jaber S, Arnal JM, Perez D, Seghboyan JM, Constantin JM, Courant P, Lefrant JY, Guerin C, Prat G, Morange $\mathrm{S}$, Roch A, Investigators AS. Neuromuscular blockers in early acute respiratory distress syndrome. N Engl J Med. 2010;363:1107-16.

110. Leatherman JW, Fluegel WL, David WS, Davies SF, Iber C. Muscle weakness in mechanically ventilated patients with severe asthma. Am J Respir Crit Care Med. 1996;153:1686-90.

111. Behbehani NA, Al-Mane F, D'Yachkova Y, Pare P, FitzGerald JM. Myopathy following mechanical ventilation for acute severe asthma: the role of muscle relaxants and corticosteroids. Chest. 1999;115:1627-31. 
112. Adnet F, Dhissi G, Borron SW, Galinski M, Rayeh F, Cupa M, Pourriat JL, Lapostolle F. Complication profiles of adult asthmatics requiring paralysis during mechanical ventilation. Intensive Care Med. 2001;27:1729-36.

113. De Jonghe B, Sharshar T, Lefaucheur JP, Authier FJ, Durand-Zaleski I, Boussarsar M, Cerf C, Renaud E, Mesrati F, Carlet J, Raphael JC, Outin H, Bastuji-Garin S, Groupe de Reflexion et d'Etude des Neuromyopathies en R. Paresis acquired in the intensive care unit: a prospective multicenter study. JAMA. 2002;288:2859-67.

114. Kesler SM, Sprenkle MD, David WS, Leatherman JW. Severe weakness complicating status asthmaticus despite minimal duration of neuromuscular paralysis. Intensive Care Med. 2009;35:157-60.

115. Huang DT, Angus DC, Moss M, Thompson BT, Ferguson ND, Ginde A, Gong MN, Gundel S, Hayden DL, Hite RD, Hou PC, Hough CL, Iwashyna TJ, Liu KD, Talmor DS, Yealy DM, Reevaluation of Systemic Early Neuromuscular Blockade Protocol Committee and the National Institutes of Health National Heart, Lung, and Blood Institute Prevention Early Treatment of Acute Lung Injury Network Investigators. Design and rationale of the reevaluation of systemic early neuromuscular blockade trial for acute respiratory distress syndrome. Ann Am Thorac Soc. 2017;14:124-33.

116. Frankel H, Jeng J, Tilly E, St Andre A, Champion H. The impact of implementation of neuromuscular blockade monitoring standards in a surgical intensive care unit. Am Surg. 1996;62:503-6.

117. Rudis MI, Sikora CA, Angus E, Peterson E, Popovich J Jr, Hyzy R, Zarowitz BJ. A prospective, randomized, controlled evaluation of peripheral nerve stimulation versus standard clinical dosing of neuromuscular blocking agents in critically ill patients. Crit Care Med. 1997;25:575-83.

118. Strange C, Vaughan L, Franklin C, Johnson J. Comparison of train-of-four and best clinical assessment during continuous paralysis. Am J Respir Crit Care Med. 1997;156:1556-61.

119. Rice TW, Wheeler AP, Bernard GR, Hayden DL, Schoenfeld DA, Ware LB, National Institutes of Health, National Heart, Lung, and Blood Institute ARDS Network. Comparison of the $\mathrm{SpO} / \mathrm{FIO} 2$ ratio and the $\mathrm{PaO} 2 / \mathrm{FIO} 2$ ratio in patients with acute lung injury or ARDS. Chest. 2007;132:410-7.

120. Minet C, Potton L, Bonadona A, Hamidfar-Roy R, Somohano CA, Lugosi M, Cartier JC, Ferretti G, Schwebel C, Timsit JF. Venous thromboembolism in the ICU: main characteristics, diagnosis and thromboprophylaxis. Crit Care. 2015;19:287.

121. Di Nisio M, van Es N, Buller HR. Deep vein thrombosis and pulmonary embolism. Lancet. 2017;388:3060-73.

122. Geerts WH, Bergqvist D, Pineo GF, Heit JA, Samama CM, Lassen MR, Colwell CW, American College of Chest Physicians. Prevention of venous thromboembolism: American College of Chest Physicians evidence-based clinical practice guidelines (8th edition). Chest. 2008;133:381S-453S.

123. Kearon C, Akl EA, Ornelas J, Blaivas A, Jimenez D, Bounameaux H, Huisman M, King CS, Morris TA, Sood N, Stevens SM, Vintch JR, Wells P, Woller SC, Moores L. Antithrombotic therapy for VTE disease: CHEST guideline and expert panel report. Chest. 2016;149:315-52.

124. Jacobson BF. Thrombosis-prevention is better than cure. S Afr Med J. 2013;103:231.

125. Shorr AF, Williams MD. Venous thromboembolism in critically ill patients. Observations from a randomized trial in sepsis. Thromb Haemost. 2009;101:139-44.

126. Levine RL, LeClerc JR, Bailey JE, Monberg MJ, Sarwat S. Venous and arterial thromboembolism in severe sepsis. Thromb Haemost. 2008;99:892-8.

127. Kaplan D, Casper TC, Elliott CG, Men S, Pendleton RC, Kraiss LW, Weyrich AS, Grissom CK, Zimmerman GA, Rondina MT. VTE incidence and risk factors in patients with severe sepsis and septic shock. Chest. 2015;148:1224-30.

128. Rondina MT, Schwertz H, Harris ES, Kraemer BF, Campbell RA, Mackman N, Grissom CK, Weyrich AS, Zimmerman GA. The septic milieu triggers expression of spliced tissue factor mRNA in human platelets. J Thromb Haemost. 2011;9:748-58. 
129. Rondina MT, Brewster B, Grissom CK, Zimmerman GA, Kastendieck DH, Harris ES, Weyrich AS. In vivo platelet activation in critically ill patients with primary 2009 influenza A(H1N1). Chest. 2012;141:1490-5.

130. Kaplan D, Rondina MT. Response. Chest. 2016;149:1107-8.

131. Ambrosetti M, Ferrarese M, Codecasa LR, Besozzi G, Sarassi A, Viggiani P, Migliori GB, Group ASTS. Incidence of venous thromboembolism in tuberculosis patients. Respiration. 2006;73:396.

132. Malek J, Rogers R, Kufera J, Hirshon JM. Venous thromboembolic disease in the HIVinfected patient. Am J Emerg Med. 2011;29:278-82.

133. Rasmussen LD, Dybdal M, Gerstoft J, Kronborg G, Larsen CS, Pedersen C, Pedersen G, Jensen J, Pedersen L, Sorensen HT, Obel N. HIV and risk of venous thromboembolism: a Danish nationwide population-based cohort study. HIV Med. 2011;12:202-10.

134. Robson SC, White NW, Aronson I, Woollgar R, Goodman H, Jacobs P. Acute-phase response and the hypercoagulable state in pulmonary tuberculosis. Br J Haematol. 1996;93:943-9.

135. White NW. Venous thrombosis and rifampicin. Lancet. 1989;2:434-5.

136. Ho KM, Chavan S, Pilcher D. Omission of early thromboprophylaxis and mortality in critically ill patients: a multicenter registry study. Chest. 2011;140:1436-46.

137. Kapoor VK. Venous thromboembolism in India. Natl Med J India. 2010;23:193-5.

138. Pandey A, Patni N, Singh M, Guleria R. Assessment of risk and prophylaxis for deep vein thrombosis and pulmonary embolism in medically ill patients during their early days of hospital stay at a tertiary care center in a developing country. Vasc Health Risk Manag. 2009;5:643-8.

139. Deheinzelin D, Braga AL, Martins LC, Martins MA, Hernandez A, Yoshida WB, Maffei F, Monachini M, Calderaro D, Campos W Jr, Sguizzatto GT, Caramelli B, Investigators TR. Incorrect use of thromboprophylaxis for venous thromboembolism in medical and surgical patients: results of a multicentric, observational and cross-sectional study in Brazil. J Thromb Haemost. 2006;4:1266-70.

140. Kamerkar DR, John MJ, Desai SC, Dsilva LC, Joglekar SJ. Arrive: a retrospective registry of Indian patients with venous thromboembolism. Indian J Crit Care Med. 2016;20:150-8.

141. Belch JJ, Lowe GD, Ward AG, Forbes CD, Prentice CR. Prevention of deep vein thrombosis in medical patients by low-dose heparin. Scott Med J. 1981;26:115-7.

142. Dahan R, Houlbert D, Caulin C, Cuzin E, Viltart C, Woler M, Segrestaa JM. Prevention of deep vein thrombosis in elderly medical in-patients by a low molecular weight heparin: a randomized double-blind trial. Haemostasis. 1986;16:159-64.

143. Fraisse F, Holzapfel L, Couland JM, Simonneau G, Bedock B, Feissel M, Herbecq P, Pordes R, Poussel JF, Roux L. Nadroparin in the prevention of deep vein thrombosis in acute decompensated COPD. The Association of Non-University Affiliated Intensive Care Specialist Physicians of France. Am J Respir Crit Care Med. 2000;161:1109-14.

144. Gardlund B. Randomised, controlled trial of low-dose heparin for prevention of fatal pulmonary embolism in patients with infectious diseases. The Heparin Prophylaxis Study Group. Lancet. 1996;347:1357-61.

145. Halkin H, Goldberg J, Modan M, Modan B. Reduction of mortality in general medical inpatients by low-dose heparin prophylaxis. Ann Intern Med. 1982;96:561-5.

146. Hirsch DR, Ingenito EP, Goldhaber SZ. Prevalence of deep venous thrombosis among patients in medical intensive care. JAMA. 1995;274:335-7.

147. Samama MM, Cohen AT, Darmon JY, Desjardins L, Eldor A, Janbon C, Leizorovicz A, Nguyen H, Olsson CG, Turpie AG, Weisslinger N. A comparison of enoxaparin with placebo for the prevention of venous thromboembolism in acutely ill medical patients. Prophylaxis in Medical Patients with Enoxaparin Study Group. N Engl J Med. 1999;341:793-800.

148. Attia J, Ray JG, Cook DJ, Douketis J, Ginsberg JS, Geerts WH. Deep vein thrombosis and its prevention in critically ill adults. Arch Intern Med. 2001;161:1268-79.

149. Geerts W, Cook D, Selby R, Etchells E. Venous thromboembolism and its prevention in critical care. J Crit Care. 2002;17:95-104. 
150. Cohen AT, Tapson VF, Bergmann JF, Goldhaber SZ, Kakkar AK, Deslandes B, Huang W, Zayaruzny M, Emery L, Anderson FA Jr, Investigators E. Venous thromboembolism risk and prophylaxis in the acute hospital care setting (ENDORSE study): a multinational crosssectional study. Lancet. 2008;371:387-94.

151. Kahn SR, Panju A, Geerts W, Pineo GF, Desjardins L, Turpie AG, Glezer S, Thabane L, Sebaldt RJ, CURVE Study Investigators. Multicenter evaluation of the use of venous thromboembolism prophylaxis in acutely ill medical patients in Canada. Thromb Res. 2007;119:145-55.

152. Khoury H, Welner S, Kubin M, Folkerts K, Haas S. Disease burden and unmet needs for prevention of venous thromboembolism in medically ill patients in Europe show underutilisation of preventive therapies. Thromb Haemost. 2011;106:600-8.

153. Parikh KC, Oh D, Sittipunt C, Kalim H, Ullah S, Aggarwal SK, Voice Asia Investigators. Venous thromboembolism prophylaxis in medical ICU patients in Asia (VOICE Asia): a multicenter, observational, cross-sectional study. Thromb Res. 2012;129:e152-8.

154. Todi SK, Sinha S, Chakraborty A, Sarkar A, Gupta S, D T. Utilization of deep venous thrombosis prophylaxis in medical/surgical intensive care units. Indian J Critical Care Med. 2003;7:103-5.

155. Kakkar N, Vasishta RK. Pulmonary embolism in medical patients: an autopsy-based study. Clin Appl Thromb Hemost. 2008;14:159-67.

156. Berlot G, Calderan C, Vergolini A, Bianchi M, Viviani M, Bussani R, Torelli L, Lucangelo U. Pulmonary embolism in critically ill patients receiving antithrombotic prophylaxis: a clinical-pathologic study. J Crit Care. 2011;26:28-33.

157. Ekwere TA, Ino-Ekanem BM, Ekanem A. Venous thromboembolism: awareness and practice of thromboprophylaxis among physicians in a tertiary-care hospital. Int J Med Biomed Res. 2015;4.

158. Majluf-Cruz A, Castro Martinez G, Herrera Cornejo MA, Liceaga-Cravioto G, EspinosaLarranaga F, Garcia-Chavez J. Awareness regarding venous thromboembolism among internal medicine practitioners in Mexico: a national cross-sectional study. Intern Med J. 2012;42:1335-41.

159. Alhazzani W, Lim W, Jaeschke RZ, Murad MH, Cade J, Cook DJ. Heparin thromboprophylaxis in medical-surgical critically ill patients: a systematic review and meta-analysis of randomized trials. Crit Care Med. 2013;41:2088-98.

160. Alikhan R, Bedenis R, Cohen AT. Heparin for the prevention of venous thromboembolism in acutely ill medical patients (excluding stroke and myocardial infarction). Cochrane Database Syst Rev. 2014:CD003747.

161. PROTECT Investigators for the Canadian Critical Care Trials Group and the Australian and New Zealand Intensive Care Society Clinical Trials Group, Cook D, Meade M, Guyatt G, Walter S, Heels-Ansdell D, Warkentin TE, Zytaruk N, Crowther M, Geerts W, Cooper DJ, Vallance S, Qushmaq I, Rocha M, Berwanger O, Vlahakis NE. Dalteparin versus unfractionated heparin in critically ill patients. N Engl J Med. 2011;364:1305-14.

162. Fowler RA, Mittmann N, Geerts W, Heels-Ansdell D, Gould MK, Guyatt G, Krahn M, Finfer S, Pinto R, Chan B, Ormanidhi O, Arabi Y, Qushmaq I, Rocha MG, Dodek P, McIntyre L, Hall R, Ferguson ND, Mehta S, Marshall JC, Doig CJ, Muscedere J, Jacka MJ, Klinger JR, Vlahakis N, Orford N, Seppelt I, Skrobik YK, Sud S, Cade JF, Cooper J, Cook D, Group CCCT, Group AaNZICSCT. Cost-effectiveness of dalteparin vs unfractionated heparin for the prevention of venous thromboembolism in critically ill patients. JAMA. 2014;312:2135-45.

163. Thirugnanam S, Pinto R, Cook DJ, Geerts WH, Fowler RA. Economic analyses of venous thromboembolism prevention strategies in hospitalized patients: a systematic review. Crit Care. 2012;16:R43.

164. Lippi G, Favaloro EJ, Cervellin G. Prevention of venous thromboembolism: focus on mechanical prophylaxis. Semin Thromb Hemost. 2011;37:237-51.

165. Ho KM, Tan JA. Stratified meta-analysis of intermittent pneumatic compression of the lower limbs to prevent venous thromboembolism in hospitalized patients. Circulation. 2013;128:1003-20. 
166. Cook DJ, Fuller HD, Guyatt GH, Marshall JC, Leasa D, Hall R, Winton TL, Rutledge F, Todd TJ, Roy P, Lacroix J, Griffith L, Willan A, for the Canadian Critical Care Trials Group. Risk factors for gastrointestinal bleeding in critically ill patients. Canadian Critical Care Trials Group. N Engl J Med. 1994;330:377-81.

167. Krag M, Perner A, Wetterslev J, Wise MP, Borthwick M, Bendel S, McArthur C, Cook D, Nielsen N, Pelosi P, Keus F, Guttormsen AB, Moller AD, Moller MH, SUP-ICU co-authors. Prevalence and outcome of gastrointestinal bleeding and use of acid suppressants in acutely ill adult intensive care patients. Intensive Care Med. 2015;41:833-45.

168. Krag M, Perner A, Wetterslev J, Wise MP, Hylander Moller M. Stress ulcer prophylaxis versus placebo or no prophylaxis in critically ill patients. A systematic review of randomised clinical trials with meta-analysis and trial sequential analysis. Intensive Care Med. 2014;40:11-22.

169. Alshamsi F, Belley-Cote E, Cook D, Almenawer SA, Alqahtani Z, Perri D, Thabane L, Al-Omari A, Lewis K, Guyatt G, Alhazzani W. Efficacy and safety of proton pump inhibitors for stress ulcer prophylaxis in critically ill patients: a systematic review and meta-analysis of randomized trials. Crit Care. 2016;20:120.

170. Krag M, Perner A, Wetterslev J, Wise MP, Borthwick M, Bendel S, Pelosi P, Keus F, Guttormsen AB, Schefold JC, Moller MH, Investigators S-I. Stress ulcer prophylaxis with a proton pump inhibitor versus placebo in critically ill patients (SUP-ICU trial): study protocol for a randomised controlled trial. Trials. 2016;17:205.

171. Alhazzani W, Guyatt G, Marshall JC, Hall R, Muscedere J, Lauzier F, Thabane L, Alshahrani M, English SW, Arabi YM, Deane AM, Karachi T, Rochwerg B, Finfer S, Daneman N, Zytaruk N, Heel-Ansdell D, Cook D, on behalf of the Canadian Critical Care Trials Group. Re-evaluating the inhibition of stress erosions (REVISE): a protocol for pilot randomized controlled trial. Ann Saudi Med. 2016;36:427-33.

172. MacLaren R, Reynolds PM, Allen RR. Histamine-2 receptor antagonists vs proton pump inhibitors on gastrointestinal tract hemorrhage and infectious complications in the intensive care unit. JAMA Intern Med. 2014;174:564-74.

173. Faleck DM, Salmasian H, Furuya EY, Larson EL, Abrams JA, Freedberg DE. Proton pump inhibitors do not increase risk for Clostridium difficile infection in the intensive care unit. Am J Gastroenterol. 2016;111:1641-8.

174. van Hooijdonk RT, Schultz MJ. Insulin and oral anti-hyperglycemic agents. In: Webb AJ, Angus DC, Finfer S, Gattinoni L, Singer M, editors. The Oxford textbook of critical care. 2015.

175. Ogetii GN, Akech S, Jemutai J, Boga M, Kivaya E, Fegan G, Maitland K. Hypoglycaemia in severe malaria, clinical associations and relationship to quinine dosage. BMC Infect Dis. 2010;10:334.

176. Schultz MJ, Harmsen RE, Spronk PE. Clinical review: strict or loose glycemic control in critically ill patients-implementing best available evidence from randomized controlled trials. Crit Care. 2010;14:223.

177. van den Berghe G, Wouters P, Weekers F, Verwaest C, Bruyninckx F, Schetz M, Vlasselaers D, Ferdinande P, Lauwers P, Bouillon R. Intensive insulin therapy in critically ill patients. N Engl J Med. 2001;345:1359-67.

178. Vlasselaers D, Milants I, Desmet L, Wouters PJ, Vanhorebeek I, van den Heuvel I, Mesotten D, Casaer MP, Meyfroidt G, Ingels C, Muller J, Van Cromphaut S, Schetz M, Van den Berghe G. Intensive insulin therapy for patients in paediatric intensive care: a prospective, randomised controlled study. Lancet. 2009;373:547-56.

179. Wiener RS, Wiener DC, Larson RJ. Benefits and risks of tight glucose control in critically ill adults: a meta-analysis. JAMA. 2008;300:933-44.

180. Griesdale DE, de Souza RJ, van Dam RM, Heyland DK, Cook DJ, Malhotra A, Dhaliwal R, Henderson WR, Chittock DR, Finfer S, Talmor D. Intensive insulin therapy and mortality among critically ill patients: a meta-analysis including NICE-SUGAR study data. CMAJ. 2009;180:821-7.

181. Friedrich JO, Chant C, Adhikari NK. Does intensive insulin therapy really reduce mortality in critically ill surgical patients? A reanalysis of meta-analytic data. Crit Care. 2010;14:324. 
182. Marik PE, Preiser JC. Toward understanding tight glycemic control in the ICU: a systematic review and metaanalysis. Chest. 2010;137:544-51.

183. Kansagara D, Fu R, Freeman M, Wolf F, Helfand M. Intensive insulin therapy in hospitalized patients: a systematic review. Ann Intern Med. 2011;154:268-82.

184. Wilson M, Weinreb J, Hoo GW. Intensive insulin therapy in critical care: a review of 12 protocols. Diabetes Care. 2007;30:1005-11.

185. Panahi Y, Mojtahedzadeh M, Zekeri N, Beiraghdar F, Khajavi MR, Ahmadi A. Metformin treatment in hyperglycemic critically ill patients: another challenge on the control of adverse outcomes. Iran J Pharm Res. 2011;10:913-9.

186. Mojtahedzadeh M, Jafarieh A, Najafi A, Khajavi MR, Khalili N. Comparison of metformin and insulin in the control of hyperglycaemia in non-diabetic critically ill patients. Endokrynol Pol. 2012;63:206-11.

187. Ansari G, Mojtahedzadeh M, Kajbaf F, Najafi A, Khajavi MR, Khalili H, Rouini MR, Ahmadi $\mathrm{H}$, Abdollahi M. How does blood glucose control with metformin influence intensive insulin protocols? Evidence for involvement of oxidative stress and inflammatory cytokines. Adv Ther. 2008;25:681-702.

188. Dondorp AM, Hoang MN, Mer M, Sepsis in Resource-Limited Settings-Expert Consensus Recommendations Group of the European Society of Intensive Care Med and the MahidolOxford Research Unit in Bangkok, Thailand. Recommendations for the management of severe malaria and severe dengue in resource-limited settings. Intensive Care Med. 2016.

189. Stang M, Wysowski DK, Butler-Jones D. Incidence of lactic acidosis in metformin users. Diabetes Care. 1999;22:925-7.

190. McWhirter JP, Pennington CR. Incidence and recognition of malnutrition in hospital. BMJ. 1994;308:945-8.

191. Dellinger RP, Levy MM, Rhodes A, Annane D, Gerlach H, Opal SM, Sevransky JE, Sprung CL, Douglas IS, Jaeschke R, Osborn TM, Nunnally ME, Townsend SR, Reinhart K, Kleinpell RM, Angus DC, Deutschman CS, Machado FR, Rubenfeld GD, Webb SA, Beale RJ, Vincent JL, Moreno R, Surviving Sepsis Campaign Guidelines Committee including the Pediatric Subgroup. Surviving sepsis campaign: international guidelines for management of severe sepsis and septic shock. Crit Care Med. 2013;41:580-637.

192. Taylor BE, SA MC, Martindale RG, Warren MM, Johnson DR, Braunschweig C, MS MC, Davanos E, Rice TW, Cresci GA, Gervasio JM, Sacks GS, Roberts PR, Compher C, Society of Critical Care Medicine; American Society for Parenteral and Enteral Nutrition. Guidelines for the provision and assessment of nutrition support therapy in the adult critically ill patient: Society of Critical Care Medicine (SCCM) and American Society for Parenteral and Enteral Nutrition (A.S.P.E.N.). Crit Care Med. 2016;44:390-438.

193. Doig GS, Heighes PT, Simpson F, Sweetman EA, Davies AR. Early enteral nutrition, provided within $24 \mathrm{~h}$ of injury or intensive care unit admission, significantly reduces mortality in critically ill patients: a meta-analysis of randomised controlled trials. Intensive Care Med. 2009;35:2018-27.

194. Kang W, Kudsk KA. Is there evidence that the gut contributes to mucosal immunity in humans? JPEN J Parenter Enteral Nutr. 2007;31:246-58.

195. Kompan L, Vidmar G, Spindler-Vesel A, Pecar J. Is early enteral nutrition a risk factor for gastric intolerance and pneumonia? Clin Nutr. 2004;23:527-32.

196. Moore EE, Jones TN. Benefits of immediate jejunostomy feeding after major abdominal trauma-a prospective, randomized study. J Trauma. 1986;26:874-81.

197. Singh G, Ram RP, Khanna SK. Early postoperative enteral feeding in patients with nontraumatic intestinal perforation and peritonitis. J Am Coll Surg. 1998;187:142-6.

198. Nguyen NQ, Fraser RJ, Bryant LK, Burgstad C, Chapman MJ, Bellon M, Wishart J, Holloway RH, Horowitz M. The impact of delaying enteral feeding on gastric emptying, plasma cholecystokinin, and peptide YY concentrations in critically ill patients. Crit Care Med. 2008;36:1469-74.

199. Heyland DK, Dhaliwal R, Drover JW, Gramlich L, Dodek P, Canadian Critical Care Clinical Practice Guidelines Committee. Canadian clinical practice guidelines for nutrition support 
in mechanically ventilated, critically ill adult patients. JPEN J Parenter Enteral Nutr. 2003;27:355-73.

200. Marik PE, Zaloga GP. Early enteral nutrition in acutely ill patients: a systematic review. Crit Care Med. 2001;29:2264-70.

201. Chuntrasakul C, Siltharm S, Chinswangwatanakul V, Pongprasobchai T, Chockvivatanavanit S, Bunnak A. Early nutritional support in severe traumatic patients. J Med Assoc Thail. 1996;79:21-6.

202. McClave SA, Martindale RG, Rice TW, Heyland DK. Feeding the critically ill patient. Crit Care Med. 2014;42:2600-10.

203. Maude RJ, Hoque G, Hasan MU, Sayeed A, Akter S, Samad R, Alam B, Yunus EB, Rahman R, Rahman W, Chowdhury R, Seal T, Charunwatthana P, Chang CC, White NJ, Faiz MA, Day NP, Dondorp AM, Hossain A. Timing of enteral feeding in cerebral malaria in resource-poor settings: a randomized trial. PLoS One. 2011;6:e27273.

204. Ibrahim EH, Mehringer L, Prentice D, Sherman G, Schaiff R, Fraser V, Kollef MH. Early versus late enteral feeding of mechanically ventilated patients: results of a clinical trial. JPEN J Parenter Enteral Nutr. 2002;26:174-81.

205. Bonten MJ, Gaillard CA, van der Hulst R, de Leeuw PW, van der Geest S, Stobberingh EE, Soeters PB. Intermittent enteral feeding: the influence on respiratory and digestive tract colonization in mechanically ventilated intensive-care-unit patients. Am J Respir Crit Care Med. 1996;154:394-9.

206. Ciocon JO, Galindo-Ciocon DJ, Tiessen C, Galindo D. Continuous compared with intermittent tube feeding in the elderly. JPEN J Parenter Enteral Nutr. 1992;16:525-8.

207. Hiebert JM, Brown A, Anderson RG, Halfacre S, Rodeheaver GT, Edlich RF. Comparison of continuous vs intermittent tube feedings in adult burn patients. JPEN J Parenter Enteral Nutr. 1981;5:73-5.

208. Kocan MJ, Hickisch SM. A comparison of continuous and intermittent enteral nutrition in NICU patients. J Neurosci Nurs. 1986;18:333-7.

209. Steevens EC, Lipscomb AF, Poole GV, Sacks GS. Comparison of continuous vs intermittent nasogastric enteral feeding in trauma patients: perceptions and practice. Nutr Clin Pract. 2002;17:118-22.

210. MacLeod JB, Lefton J, Houghton D, Roland C, Doherty J, Cohn SM, Barquist ES. Prospective randomized control trial of intermittent versus continuous gastric feeds for critically ill trauma patients. J Trauma. 2007;63:57-61.

211. McClave SA, DeMeo MT, DeLegge MH, DiSario JA, Heyland DK, Maloney JP, Metheny NA, Moore FA, Scolapio JS, Spain DA, Zaloga GP. North American Summit on aspiration in the critically ill patient: consensus statement. JPEN J Parenter Enteral Nutr. 2002;26:S80-5.

212. Desai SV, McClave SA, Rice TW. Nutrition in the ICU: an evidence-based approach. Chest. 2014;145:1148-57.

213. SM A-K, LaPointe NM, Kramer JM, Califf RM. What clinicians should know about the QT interval. JAMA. 2003;289:2120-7.

214. Drakulovic MB, Torres A, Bauer TT, Nicolas JM, Nogue S, Ferrer M. Supine body position as a risk factor for nosocomial pneumonia in mechanically ventilated patients: a randomised trial. Lancet. 1999;354:1851-8.

215. van Nieuwenhoven CA, Vandenbroucke-Grauls C, van Tiel FH, Joore HC, van Schijndel RJ, van der Tweel I, Ramsay G, Bonten MJ. Feasibility and effects of the semirecumbent position to prevent ventilator-associated pneumonia: a randomized study. Crit Care Med. 2006;34:396-402.

216. Simmons-Trau D, Cenek P, Counterman J, Hockenbury D, Litwiller L. Reducing VAP with 6 Sigma. Nurs Manag. 2004;35:41-5.

217. Zack JE, Garrison T, Trovillion E, Clinkscale D, Coopersmith CM, Fraser VJ, Kollef $\mathrm{MH}$. Effect of an education program aimed at reducing the occurrence of ventilator-associated pneumonia. Crit Care Med. 2002;30:2407-12.

218. Dickerson RN, Pitts SL, Maish GO 3rd, Schroeppel TJ, Magnotti LJ, Croce MA, Minard G, Brown RO. A reappraisal of nitrogen requirements for patients with critical illness and trauma. J Trauma Acute Care Surg. 2012;73:549-57. 
219. McClave SA, Martindale RG, Kiraly L. The use of indirect calorimetry in the intensive care unit. Curr Opin Clin Nutr Metab Care. 2013;16:202-8.

220. McClave SA, Martindale RG, Vanek VW, McCarthy M, Roberts P, Taylor B, Ochoa JB, Napolitano L, Cresci G, ASPEN Board of Directors, American College of Critical Care Medicine, Society of Critical Care Medicine. Guidelines for the provision and assessment of nutrition support therapy in the adult critically ill patient: Society of Critical Care Medicine (SCCM) and American Society for Parenteral and Enteral Nutrition (A.S.P.E.N.). JPEN J Parenter Enteral Nutr. 2009;33:277-316.

221. Neelemaat F, van Bokhorst de van der Schueren MA, Thijs A, Seidell JC, Weijs PJ. Resting energy expenditure in malnourished older patients at hospital admission and three months after discharge: predictive equations versus measurements. Clin Nutr. 2012;31:958-66.

222. Allingstrup MJ, Esmailzadeh N, Wilkens Knudsen A, Espersen K, Hartvig Jensen T, Wiis J, Perner A, Kondrup J. Provision of protein and energy in relation to measured requirements in intensive care patients. Clin Nutr. 2012;31:462-8.

223. Burge JC, Goon A, Choban PS, Flancbaum L. Efficacy of hypocaloric total parenteral nutrition in hospitalized obese patients: a prospective, double-blind randomized trial. JPEN J Parenter Enteral Nutr. 1994;18:203-7.

224. Choban PS, Burge JC, Scales D, Flancbaum L. Hypoenergetic nutrition support in hospitalized obese patients: a simplified method for clinical application. Am J Clin Nutr. 1997;66:546-50.

225. Choban PS, Dickerson RN. Morbid obesity and nutrition support: is bigger different? Nutr Clin Pract. 2005;20:480-7.

226. Angstwurm MW, Engelmann L, Zimmermann T, Lehmann C, Spes CH, Abel P, Strauss R, Meier-Hellmann A, Insel R, Radke J, Schuttler J, Gartner R. Selenium in Intensive Care (SIC): results of a prospective randomized, placebo-controlled, multiple-center study in patients with severe systemic inflammatory response syndrome, sepsis, and septic shock. Crit Care Med. 2007;35:118-26.

227. Berger MM, Chiolero RL. Antioxidant supplementation in sepsis and systemic inflammatory response syndrome. Crit Care Med. 2007;35:S584-90.

228. Mishra V, Baines M, Perry SE, McLaughlin PJ, Carson J, Wenstone R, Shenkin A. Effect of selenium supplementation on biochemical markers and outcome in critically ill patients. Clin Nutr. 2007;26:41-50.

229. Schneider A, Markowski A, Momma M, Seipt C, Luettig B, Hadem J, Wilhelmi M, Manns MP, Wedemeyer J. Tolerability and efficacy of a low-volume enteral supplement containing key nutrients in the critically ill. Clin Nutr. 2011;30:599-603.

230. Manzanares W, Lemieux M, Elke G, Langlois PL, Bloos F, Heyland DK. High-dose intravenous selenium does not improve clinical outcomes in the critically ill: a systematic review and meta-analysis. Crit Care. 2016;20:356.

231. Barr J, Hecht M, Flavin KE, Khorana A, Gould MK. Outcomes in critically ill patients before and after the implementation of an evidence-based nutritional management protocol. Chest. 2004; 125:1446-57.

232. Doig GS, Simpson F, Finfer S, Delaney A, Davies AR, Mitchell I, Dobb G, Nutrition Guidelines Investigators of the ANZICS Clinical Trials Group. Effect of evidence-based feeding guidelines on mortality of critically ill adults: a cluster randomized controlled trial. JAMA. 2008;300:2731-41.

233. Heyland DK, Murch L, Cahill N, McCall M, Muscedere J, Stelfox HT, Bray T, Tanguay T, Jiang X, Day AG. Enhanced protein-energy provision via the enteral route feeding protocol in critically ill patients: results of a cluster randomized trial. Crit Care Med. 2013;41:2743-53.

234. Spain DA, McClave SA, Sexton LK, Adams JL, Blanford BS, Sullins ME, Owens NA, Snider HL. Infusion protocol improves delivery of enteral tube feeding in the critical care unit. JPEN J Parenter Enteral Nutr. 1999;23:288-92.

235. Chan S, McCowen KC, Blackburn GL. Nutrition management in the ICU. Chest. 1999;115:145S-8S.

236. Dare AJ, Fu SH, Patra J, Rodriguez PS, Thakur JS, Jha P, Million Death Study Collaborators. Renal failure deaths and their risk factors in India 2001-13: nationally representative estimates from the Million Death Study. Lancet Glob Health. 2017;5:e89-95. 
237. Lameire NH, Bagga A, Cruz D, De Maeseneer J, Endre Z, Kellum JA, Liu KD, Mehta RL, Pannu N, Van Biesen W, Vanholder R. Acute kidney injury: an increasing global concern. Lancet. 2013;382:170-9.

238. Ponce D, Berbel MN, Regina de Goes C, Almeida CT, Balbi AL. High-volume peritoneal dialysis in acute kidney injury: indications and limitations. Clin J Am Soc Nephrol. 2012;7:887-94.

239. Callegari J, Antwi S, Wystrychowski G, Zukowska-Szczechowska E, Levin NW, Carter M. Peritoneal dialysis as a mode of treatment for acute kidney injury in sub-Saharan Africa. Blood Purif. 2013;36:226-30.

240. Chijioke A, Makusidi AM, Rafiu MO. Factors influencing hemodialysis and outcome in severe acute renal failure from Ilorin, Nigeria. Saudi J Kidney Dis Transpl. 2012;23:391-6.

241. Godara SM, Kute VB, Trivedi HL, Vanikar AV, Shah PR, Gumber MR, Patel HV, Gumber VM. Clinical profile and outcome of acute kidney injury related to pregnancy in developing countries: a single-center study from India. Saudi J Kidney Dis Transpl. 2014;25:906-11.

242. Kilonzo KG, Ghosh S, Temu SA, Maro V, Callegari J, Carter M, Handelman G, Finkelstein FO, Levin N, Yeates K. Outcome of acute peritoneal dialysis in northern Tanzania. Perit Dial Int. 2012;32:261-6.

243. Maoujoud O, Zajjari Y, Asseraji M, Aatif T, Ahid S, Oualim Z. Commentary: the practice of dialysis in the intensive care unit in a developing country. Ethn Dis. 2014;24:226-8.

244. Okunola OO, Ayodele OE, Adekanle AD. Acute kidney injury requiring hemodialysis in the tropics. Saudi J Kidney Dis Transpl. 2012;23:1315-9.

245. Shah PR, Gireesh MS, Kute VB, Vanikar AV, Gumber MR, Patel HV, Goplani KR, Trivedi HL. Renal involvement in sepsis: a prospective single-center study of 136 cases. Saudi J Kidney Dis Transpl. 2013;24:620-9.

246. Ademola AD, Asinobi AO, Ogunkunle OO, Yusuf BN, Ojo OE. Peritoneal dialysis in childhood acute kidney injury: experience in southwest Nigeria. Perit Dial Int. 2012;32:267-72.

247. Diarrassouba G, Adonis-Koffy L, Niamien E, Yaokreh JB, Coulibaly PA. Acute peritoneal dialysis in African pediatric area experience of pediatric nephrology unit of Yopougon University Hospital (Abidjan, Cote d'Ivoire). Blood Purif. 2015;39:141-4.

248. Mishra OP, Gupta AK, Pooniya V, Prasad R, Tiwary NK, Schaefer F. Peritoneal dialysis in children with acute kidney injury: a developing country experience. Perit Dial Int. 2012;32:431-6.

249. Rifai AO, Murad LB, Sekkarie MA, Al-Makki AA, Zanabli AR, Kayal AA, Soudan KA. Continuous venovenous hemofiltration using a stand-alone blood pump for acute kidney injury in field hospitals in Syria. Kidney Int. 2015;87:254-61.

250. Smoyer WE, Finkelstein FO, McCulloch M, Carter M, Brusselmans A, Feehally J. Saving young lives: provision of acute dialysis in low-resource settings. Lancet. 2015;386:2056.

251. Burki T. Tanzania's model peritoneal dialysis programme. Lancet. 2015;385:1935-6.

252. Callegari JG, Kilonzo KG, Yeates KE, Handelman GJ, Finkelstein FO, Kotanko P, Levin NW, Carter M. Peritoneal dialysis for acute kidney injury in sub-Saharan Africa: challenges faced and lessons learned at Kilimanjaro Christian Medical Centre. Kidney Int. 2012;81:331-3.

253. Smoyer WE, Finkelstein FO, McCulloch MI, Carter M, Brusselmans A, Feehally J. "Saving Young Lives" with acute kidney injury: the challenge of acute dialysis in low-resource settings. Kidney Int. 2016;89:254-6.

254. Phu NH, Hien TT, Mai NT, Chau TT, Chuong LV, Loc PP, Winearls C, Farrar J, White N, Day N. Hemofiltration and peritoneal dialysis in infection-associated acute renal failure in Vietnam. N Engl J Med. 2002;347:895-902.

255. Chionh CY, Soni SS, Finkelstein FO, Ronco C, Cruz DN. Use of peritoneal dialysis in AKI: a systematic review. Clin J Am Soc Nephrol. 2013;8:1649-60.

256. Bagshaw SM, Brophy PD, Cruz D, Ronco C. Fluid balance as a biomarker: impact of fluid overload on outcome in critically ill patients with acute kidney injury. Crit Care. 2008;12:169.

257. Murphy CV, Schramm GE, Doherty JA, Reichley RM, Gajic O, Afessa B, Micek ST, Kollef $\mathrm{MH}$. The importance of fluid management in acute lung injury secondary to septic shock. Chest. 2009;136:102-9. 
258. Payen D, de Pont AC, Sakr Y, Spies C, Reinhart K, Vincent JL, Investigators SOiAIP. A positive fluid balance is associated with a worse outcome in patients with acute renal failure. Crit Care. 2008;12:R74.

259. Rivers EP. Fluid-management strategies in acute lung injury-liberal, conservative, or both? N Engl J Med. 2006;354:2598-600.

260. Sakr Y, Vincent JL, Reinhart K, Groeneveld J, Michalopoulos A, Sprung CL, Artigas A, Ranieri VM, Sepsis Occurence in Acutely Ill Patients Investigators. High tidal volume and positive fluid balance are associated with worse outcome in acute lung injury. Chest. 2005;128:3098-108.

261. Acheampong A, Vincent JL. A positive fluid balance is an independent prognostic factor in patients with sepsis. Crit Care. 2015;19:251.

262. Alsous F, Khamiees M, DeGirolamo A, Amoateng-Adjepong Y, Manthous CA. Negative fluid balance predicts survival in patients with septic shock: a retrospective pilot study. Chest. 2000;117:1749-54.

263. National Heart, Lung, and Blood Institute Acute Respiratory Distress Syndrome (ARDS) Clinical Trials Network, Wiedemann HP, Wheeler AP, Bernard GR, Thompson BT, Hayden D, deBoisblanc B, Connors AF Jr, Hite RD, Harabin AL. Comparison of two fluid-management strategies in acute lung injury. N Engl J Med. 2006;354:2564-2575.

264. Malbrain ML, Marik PE, Witters I, Cordemans C, Kirkpatrick AW, Roberts DJ, Van Regenmortel N. Fluid overload, de-resuscitation, and outcomes in critically ill or injured patients: a systematic review with suggestions for clinical practice. Anaesthesiol Intensive Ther. 2014;46:361-80.

265. Andrews B, Muchemwa L, Kelly P, Lakhi S, Heimburger DC, Bernard GR. Simplified severe sepsis protocol: a randomized controlled trial of modified early goal-directed therapy in Zambia. Crit Care Med. 2014;42:2315-24.

266. Eskesen TG, Wetterslev M, Perner A. Systematic review including re-analyses of 1148 individual data sets of central venous pressure as a predictor of fluid responsiveness. Intensive Care Med. 2016;42:324-32.

267. Magder S. Central venous pressure: a useful but not so simple measurement. Crit Care Med. 2006;34:2224-7.

268. Mager DE, Lin SX, Blum RA, Lates CD, Jusko WJ. Dose equivalency evaluation of major corticosteroids: pharmacokinetics and cell trafficking and cortisol dynamics. J Clin Pharmacol. 2003;43:1216-27.

269. Adrenal cortical steroids drug facts and comparisons. St. Louis: Facts and Comparisons, Inc.; 1997. p. 122-28.

270. Schimmer BP, Funder JW. ACTH, adrenal steroids, and pharmacology of the adrenal cortex. In: Brunton LL, Chabner BA, Knollman BC, editors. Goodman and Gilman's the pharmacological basis of therapeutics. New York: McGraw-Hill; 2011.

Open Access This chapter is licensed under the terms of the Creative Commons Attribution 4.0 International License (http://creativecommons.org/licenses/by/4.0/), which permits use, sharing, adaptation, distribution and reproduction in any medium or format, as long as you give appropriate credit to the original author(s) and the source, provide a link to the Creative Commons license and indicate if changes were made.

The images or other third party material in this chapter are included in the chapter's Creative Commons license, unless indicated otherwise in a credit line to the material. If material is not included in the chapter's Creative Commons license and your intended use is not permitted by statutory regulation or exceeds the permitted use, you will need to obtain permission directly from the copyright holder. 